\title{
The mobile Water vapor Aerosol Raman LIdar and its implication in the framework of the HyMeX and ChArMEx programs: application to a dust transport process
}

\author{
P. Chazette, F. Marnas, and J. Totems \\ Laboratoire des Sciences du Climat et de l'Environnement (LSCE), UMR8212, Laboratoire mixte CEA-CNRS-UVSQ, CEA \\ Saclay, 91191 Gif-sur-Yvette, France \\ Correspondence to: P. Chazette (patrick.chazette@1sce.ipsl.fr)
}

Received: 3 November 2013 - Published in Atmos. Meas. Tech. Discuss.: 10 December 2013

Revised: 6 March 2014 - Accepted: 2 April 2014 - Published: 10 June 2014

\begin{abstract}
The increasing importance of the coupling of water and aerosol cycles in environmental applications requires observation tools that allow simultaneous measurements of these two fundamental processes for climatological and meteorological studies. For this purpose, a new mobile Raman lidar, WALI (Water vapor and Aerosol LIdar), has been developed and implemented within the framework of the international HyMeX and ChArMEx programs. This paper presents the key properties of this new device and its first applications to scientific studies. The lidar uses an eye-safe emission in the ultraviolet range at $354.7 \mathrm{~nm}$ and a set of compact refractive receiving telescopes. Cross-comparisons between rawinsoundings performed from balloon or aircraft and lidar measurements have shown a good agreement in the derived water vapor mixing ratio (WVMR). The discrepancies are generally less than $0.5 \mathrm{~g} \mathrm{~kg}^{-1}$ and therefore within the error bars of the respective instruments. A detailed study of the uncertainty of the WVMR retrieval was conducted and shows values between 7 and $11 \%$, which is largely constrained by the quality of the lidar calibration. It also proves that the lidar is able to measure the WVMR during daytime over a range of about $1 \mathrm{~km}$. In addition the WALI system provides measurements of aerosol optical properties such as the lidar ratio (LR) or the particulate depolarization ratio (PDR). An important example of scientific application addressing the main objectives of the HyMeX and ChArMEx programs is then presented, following an event of desert dust aerosols over the Balearic Islands in October 2012. This dust intrusion may have had a significant impact on the intense precipitations that occurred over southwestern France and the Spanish Mediterranean coasts. During this event, the LR and
\end{abstract}

PDR values obtained are in the ranges of $\sim 45-63 \pm 6$ and $0.10-0.19 \pm 0.01 \mathrm{sr}$, respectively, which is representative of dust aerosols. The dust layers are also shown to be associated with significant WVMR, i.e., between 4 and $6.7 \mathrm{~g} \mathrm{~kg}^{-1}$.

\section{Introduction}

By the end of the 21st century, climate models are predicting a significant increase in the loss of fresh water in densely populated areas. For instance, the decrease of fresh water reserves around the Mediterranean Sea has been assessed to be $40 \%$ higher for the period 2070-2090 as compared to 19501999 (Sanchez-Gomez et al., 2009). These results should be considered in the context of rising anthropogenic pressure in the Mediterranean region, with a population growth expected in the range of $300 \%$ around the Mediterranean Basin within the next 25 years (with more than 500 million inhabitants). The Mediterranean area is thus identified as a hot spot in the projections of future climate change (Giorgi and Lionello, 2008) where the water vapor mixing ratio (WVMR) is a key meteorological parameter for the energy balance of the atmosphere (e.g., Held and Soden, 2000; IPCC, 2013).

Moreover, it is now known that the cycles of aerosols, clouds and water vapor are closely coupled within climate change scenarios. Water vapor is involved in the aerosol and cloud formation when aerosols contain hygroscopic components (e.g., Larson and Taylor, 1983; Rood et al., 1987; Randriamiarisoa et al., 2006) and thus influences the Earthatmosphere radiative balance. Aerosol hydration remains one 
of the largest sources of uncertainty in climate models (e.g., Boucher and Anderson, 1995; Haywood et al., 1997; IPCC, 2013). Aerosols also lead to a reduction in atmospheric visibility, which impacts socioeconomic activities. As the densely populated areas of the planet are especially vulnerable to changes in the coupled cycles of water and aerosol, precise measurements are now necessary to assess the model uncertainties in both the water vapor mixing ratio and the aerosol amounts in the lower and middle troposphere.

As written by Whiteman et al. (1992), the lidar technique is a well-established tool for measuring the water vapor mixing ratio in the atmosphere. Melfi et al. (1969) and Cooney (1970) showed as early as the late 1960s that Raman lidar is a powerful tool for this type of measurement, and Vaughan et al. (1988) used, for the first time, a Raman lidar to perform water vapor mixing ratio measurements up to the tropopause. Following these pioneer works, Ansmann et al. (1992) performed simultaneous measurements of the water vapor mixing ratio and aerosol optical properties, Turner et al. (1999) used Raman lidar in continuous measurements in the framework of the atmospheric radiation measurement program (ARM), and Veselovskii et al. (2000) also reported profiles of the water vapor mixing ratio in the troposphere. More recently, the German Meteorological Service (DWD) has been equipped with a Raman lidar (Reichardt et al., 2012). The differential absorption lidar technique (e.g., Higdon et al., 1994; Bruneau et al., 2001) could also be used but requires greater instrumental constraints and makes it difficult to comply with eye-safety conditions. Lidar is also an often-used instrument for aerosol survey (Fiocco and Grams, 1964) and particularly Raman lidar (e.g., Melfi et al., 1989; Ansmann et al., 1992; Turner et al., 1999). More recently, an eye-safe, compact and light nitrogen-Raman lidar was developed at Laboratoire des Sciences du Climat et de l'Environnement (LSCE) to track the aerosol pollution around Paris as well as the ash emitted in the atmosphere by the Eyjafjallajökull volcano (Royer et al., 2011; Chazette et al., 2012a, b). In the framework of the scientific programs Hydrological cycle in the Mediterranean eXperiment (HyMeX, http://www. hymex.org/) and Chemistry-Aerosol Mediterranean Experiment (ChArMEx, http://www.mistrals-home.org), the instrumental evolution of such a lidar was the addition of a water vapor Raman channel.

We present in this paper the new transportable eye-safe and mobile Water vapor and Aerosol Raman LIdar (WALI) that is able to measure simultaneously the water vapor mixing ratio (WVMR) and the aerosol optical properties with sufficient reliability for meteorological and climatological studies in the lower and middle troposphere. The first results obtained for the retrieval of the WVMR and aerosol optical properties will be presented and discussed hereafter following the campaign (in fall 2012) of the HyMeX/IODA-MED (Innovative Observing and Data Assimilation systems for the MEDiterranean Weather) program. The data sets gathered on aerosol properties also represents useful measurements for the ChArMEx program.

In Sect. 2, the Raman lidar will be presented along with the experimental setup. The classical theoretical approaches for the retrieval of the WVMR and aerosol optical properties will also be reiterated. For the lidar calibration, a comparison to WVMR vertical soundings performed by rawinsoundings and aircraft measurements will be presented in Sect. 3. The main uncertainties will be assessed and discussed in Sect. 4. In Sect. 5, we will analyze an example of a dust event observed in the framework of the HyMeX fall 2012 campaign. Finally, the conclusions, Sect. 6, will review the main characteristics of the instrument and the first results obtained.

\section{Experimental and theoretical tools}

The WALI instrument as well as the signal processing used for the retrieval of both the WVMR and the aerosol optical properties are described here. The experimental sites where lidar measurements have been performed are also presented.

\subsection{Technical characteristics of WALI}

The WALI instrument was developed at LSCE based on the same technology as its precursor instruments LESAA (Lidar pour l'Etude et le Suivi de l'Aérosol Atmosphérique, (Chazette et al., 2005) and LAUVA (Lidar Aérosol UltraViolet Aéroporté (Chazette et al., 2007; Raut and Chazette, 2009). It is a laboratory-made instrument mainly dedicated to atmospheric research activities.

The lidar operates with an emitted wavelength of $354.7 \mathrm{~nm}$ and is designed to fulfill eye-safety standards (EN 608251). Its emitter is a pulsed Nd:YAG laser (model BRILLANT) manufactured by QUANTEL ${ }^{\mathrm{TM}}$ (www.quantel.com). The acquisition system is based on a PXI (PCI eXtensions for Instrumentation) technology with 12 bit digitizers at 200 $\mathrm{MS} \mathrm{s}^{-1}$ (megasamples per second) manufactured by National Instruments ${ }^{\mathrm{TM}}$. Its main characteristics are summarized in Table 1. During all the experiments the acquisition was performed by averaging 1000 laser shots, leading to a temporal sampling close to $1 \mathrm{~min}$. The UV pulse energy is $\sim 60 \mathrm{~mJ}$ and the pulse repetition rate is $20 \mathrm{~Hz}$.

A schematic representation of WALI is given in Fig. 1. The receiver is composed of three distinct detection modules using small collector telescopes with a diameter of $15 \mathrm{~cm}$. The total number of detection channels is four. Note that the reason for having separate paths for the two Raman channels is to independently set up the optics and electronics of each channel in order to retain as much flexibility as possible. Hence, we can easily replace a detection module to optimize the lidar performance.

Using short focal length refractive telescopes instead of a reflector ensures a low-altitude overlap for the lidar beams and increases the overall stability, transmittance and 
Table 1. Main technical characteristics of the WALI instrument.

\begin{tabular}{ll}
\hline Laser & $\mathrm{Nd}$ Yag \\
\hline Energy & $60 \mathrm{~mJ}$ at $355 \mathrm{~nm}$ \\
Frequency & $20 \mathrm{~Hz}$ \\
Reception channels & Elastic total $354.67 \mathrm{~nm}$ \\
& Elastic $-354.67 \mathrm{~nm}$ \\
& Raman $\mathrm{N}_{2} 386.63 \mathrm{~nm}$ \\
& Raman $\mathrm{H}_{2} \mathrm{O} 407.5 \mathrm{~nm}$ \\
Reception diameters & $15 \mathrm{~cm}$ \\
Field of view & $\sim 2.3 \mathrm{mrad}$ \\
Full overlap & $\sim 300 \mathrm{~m}$ \\
Detector & Photomultiplier tubes \\
Filter bandwidths & $0.2-0.3 \mathrm{~nm}$ \\
Vertical sampling & $0.75 \mathrm{~m}$ (analog) \\
& $15 \mathrm{~m}$ (photon counting) \\
Vertical resolution & $\sim 30 \mathrm{~m}$ \\
Acquisition system & PXI technology at $200 \mathrm{MHz}$ \\
\hline
\end{tabular}

compactness of the instrument. The wide field of view (FOV) $\sim 2.3 \mathrm{mrad}$ allows a full overlap of the transmission and reception paths beyond $\sim 200-300 \mathrm{~m}$. On each channel, optical detection is performed by a photomultiplier tube placed behind an interference filter and a focusing lens. The amplification gain of the tube between its anode and cathode is directly linked to the input high voltage (HV) chosen by the lidar acquisition software. HV variation allows optimizing the detection dynamic range for both nighttime and daytime measurements (with strong sky background light). As separate HV supply units for the Raman nitrogen and water vapor channels are used, a careful calibration of the relative channel gain versus HV has to be performed.

The first module is dedicated to the detection of the elastic molecular, aerosol and cloud backscatter from the atmosphere. Two different channels are implemented on that module to detect (i) the total (co-polarized and cross-polarized with respect to the polarized laser emission) and (ii) the cross-polarized backscatter coefficients of the atmosphere. The separation between the two beams is carried out using a beam splitter and a Brewster plate. The two interference filters (IF1), with spectral bandwidths of $0.2 \mathrm{~nm}$ (full width at half maximum, FWHM), are manufactured by Barr Associates $^{\mathrm{TM}}$. This reception channel design is similar to the one used in previous studies of tropospheric aerosols (e.g., Royer et al., 2011; Chazette et al., 2012a). The second and third channels are dedicated to the measurements of the inelastic nitrogen $\left(\mathrm{N}_{2}\right.$ channel) and water vapor $\left(\mathrm{H}_{2} \mathrm{O}\right.$ channel $)$ Raman backscattered signals. They collect the backscattered Stokes component of the inelastic vibrational Raman scattering because this process is much more intense at the typical tropospheric temperatures (compared to the anti-Stokes component of Raman scattering). Such scattering happens at a longer wavelength than that emitted, i.e., $\sim 386.6$ and $\sim 407.5 \mathrm{~nm}$ for the $\mathrm{N}_{2}$ and $\mathrm{H}_{2} \mathrm{O}$ channel, respectively. The

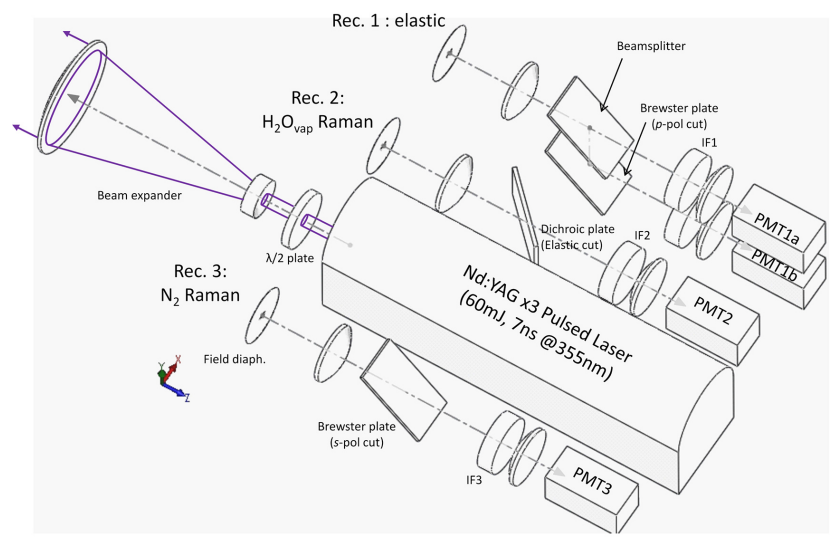

Figure 1. Schematic representation of the WALI system. The receiver refractive telescopes, located on each path before the field diaphragm, have been omitted for clarity. The three separate detection modules are highlighted with their main components. The emission size is adapted using a beam expander to fulfill eye-safe conditions. The elastic $(354.67 \mathrm{~nm})$ detection module is composed of two polarization channels: total and cross-polarized. The separation of the radiation over the two channels is done using a beam-splitter plate. The $\mathrm{N}_{2}$-Raman detection module $(386.63 \mathrm{~nm})$ is equipped with a $386.63 \mathrm{~nm}$ working-wavelength Brewster plate to get rid of half of the sky background. The $\mathrm{H}_{2} \mathrm{O}$-channel detection module $(407.5 \mathrm{~nm})$ is equipped with an additional dichroic plate to ensure a total rejection of the fundamental radiation at $354.67 \mathrm{~nm}$.

measured water vapor Raman signal is $\sim 4$ orders of magnitude ( $\sim 3$ orders for the nitrogen Raman signal) smaller than the elastic backscattered signal. Therefore, the $\mathrm{H}_{2} \mathrm{O}$ channel requires an extremely high rejection of all radiation apart from the Raman Stokes central peak, with a transmission ratio approaching 10 orders of magnitude, allowing a complete rejection of the elastic Rayleigh-Mie return (Whiteman et al., 1992, 2007). This is done by using a dichroic plate, as shown in Fig. 1, coupled with a specific interference filter. The spectral bandwidth of this interference filter (IF3), also manufactured by Barr Associates ${ }^{\mathrm{TM}}$, is $0.3 \mathrm{~nm}$ in order to optimize the contribution of the rotational lines considering the signal-to-noise ratio. The $\mathrm{N}_{2}$ channel is equipped with both a Brewster plate to decrease the background sky contribution and a Barr Associate ${ }^{\mathrm{TM}}$ interference filter (IF2) with a $0.2 \mathrm{~nm}$ spectral bandwidth. Note that, considering the narrow spectral bandwidths of the interference filters used here, the Raman backscatter cross sections do not depend on the atmospheric temperature (Bribes et al., 1976; Penney and Lapp, 1976; Whiteman et al., 1992).

\subsection{Lidar signal parameterization}

The range-corrected lidar signals $S_{\lambda}$ at wavelength $\lambda$ of a ground-based lidar located at altitude $z_{\mathrm{G}}$ above mean sea level (a.m.s.l.) is given as a function of the backscatter coefficient $\beta_{j}$, as is the aerosol (molecular) extinction coefficient $\alpha_{\mathrm{a}(\mathrm{m})}$. It depends on the altitude $z$ by the basic lidar equation 
(e.g., Measures, 1984)

$$
S_{\lambda}(z)=C_{\lambda} \cdot F_{\lambda}(z) \cdot \beta_{\lambda}(z)
$$

$\cdot \exp \left(-\int_{z_{\mathrm{G}}}^{z}\left[\left(1+\eta_{\mathrm{m} \lambda}\right) \cdot \alpha_{\mathrm{m}}\left(z^{\prime}\right)+\left(1+\eta_{\mathrm{a} \lambda}\left(z^{\prime}\right)\right) \cdot \alpha_{\mathrm{a}}\left(z^{\prime}\right)\right] \cdot \mathrm{d} z^{\prime}\right)$,

where (i) for the elastic channel at $\lambda=354.67 \mathrm{~nm}$ (subscript $\mathrm{E}$ hereafter), $\beta_{\mathrm{E}}(z)=k_{\mathrm{f}} \frac{3 \alpha_{\mathrm{m}}(z)}{8 \pi}+\frac{\alpha_{\mathrm{a}}(z)}{L R(z)}$, which is the sum of the molecular (subscript $\mathrm{m}, \beta_{\mathrm{m}}(z)=k_{\mathrm{f}} \frac{3 \alpha_{\mathrm{m}}(z)}{8 \pi}$ ) and the aerosol (subscript a, $\beta_{\mathrm{a}}(z)=\frac{\alpha_{\mathrm{a}}(z)}{\mathrm{LR}(z)}$ ) contributions, with $k_{\mathrm{f}}$ the King factor of air (King, 1923) and LR the lidar ratio (particle extinction-to-backscatter ratio); (ii) for the nitrogen Raman channel at $\lambda=386.63 \mathrm{~nm}$ (subscript $\mathrm{N}$ hereafter), $\beta_{\mathrm{N}}(z)=N_{\mathrm{N}}(z) \cdot \sigma_{\mathrm{N}}^{\pi}$, with the nitrogen density profile denoted as $N_{\mathrm{N}}(z)$; and (iii) for the water vapor Raman channel at $\lambda=407.5 \mathrm{~nm}$ (subscript $\mathrm{H}$ hereafter), $\beta_{\mathrm{H}}(z)=N_{\mathrm{H}}(z) \cdot \sigma_{\mathrm{H}}^{\pi}$, with the water vapor density profile denoted as $N_{\mathrm{H}}(z)$. The $x$ in $\sigma_{x}^{\pi}$ is the Raman differential backscatter cross-section, with $x$ standing for either nitrogen $(x=N)$ or water vapor $(x=H)$. The coefficients $\eta_{\mathrm{m} \lambda}=\left(\frac{\lambda}{354.67}\right)^{-4.09}$ and $\eta_{\mathrm{a} \lambda}(z)=$ $\left(\frac{\lambda}{354.67}\right)^{-A(z)}$ are used to account for the spectrally dependent effects due to the molecules and aerosols (via the Ångström exponent $A$ ), respectively. Note that only zenithal lidar measurements have been performed within this work. $C_{\lambda}$ are the instrumental constants. $F_{\lambda}$ are the overlap functions, which were experimentally measured during the campaign for each channel and are shown in Fig. 2. Because the WALI lidar is only pointing to zenith, we cannot easily assess the overlap factors. Hence, the overlap factor of the elastic channel is initially determined using the comparison with another calibrated lidar. The overlap factor is checked during the experiment when homogenous atmospheric layers are present, mainly in the early morning. With the presence of clouds above the planetary boundary layer, the condition of homogeneity is often respected and such situations could also be used to check the overlap factor. The same approach is used for the $\mathrm{N}_{2}$ channel. The overlap function of the $\mathrm{H}_{2} \mathrm{O}$ channel is deduced from both that of the $\mathrm{N}_{2}$ channel and the direct calibration in terms of WVMR hereafter presented. Overlap is not complete below $\sim 0.7 \mathrm{~km}$ because the field diaphragm did not collect the entire image field in the optical configuration used. Hence, this overlap factor correction including the calibration process has to be applied.

The molecular extinction and backscatter coefficients are determined based on the polynomial approximation proposed by Nicolet (1984) using a reference atmospheric density calculated from ancillary measurements (e.g., Chazette et al., 2012a). The uncertainty on the a priori knowledge of the molecular contribution has been previously assessed to be lower than $2 \%$ (Chazette et al., 2010). Considering $k_{\mathrm{f}}=1$ leads to an overestimation on the molecular backscatter coefficient of only $1.5 \%$ at $355 \mathrm{~nm}$ (Collis and Russel, 1976).
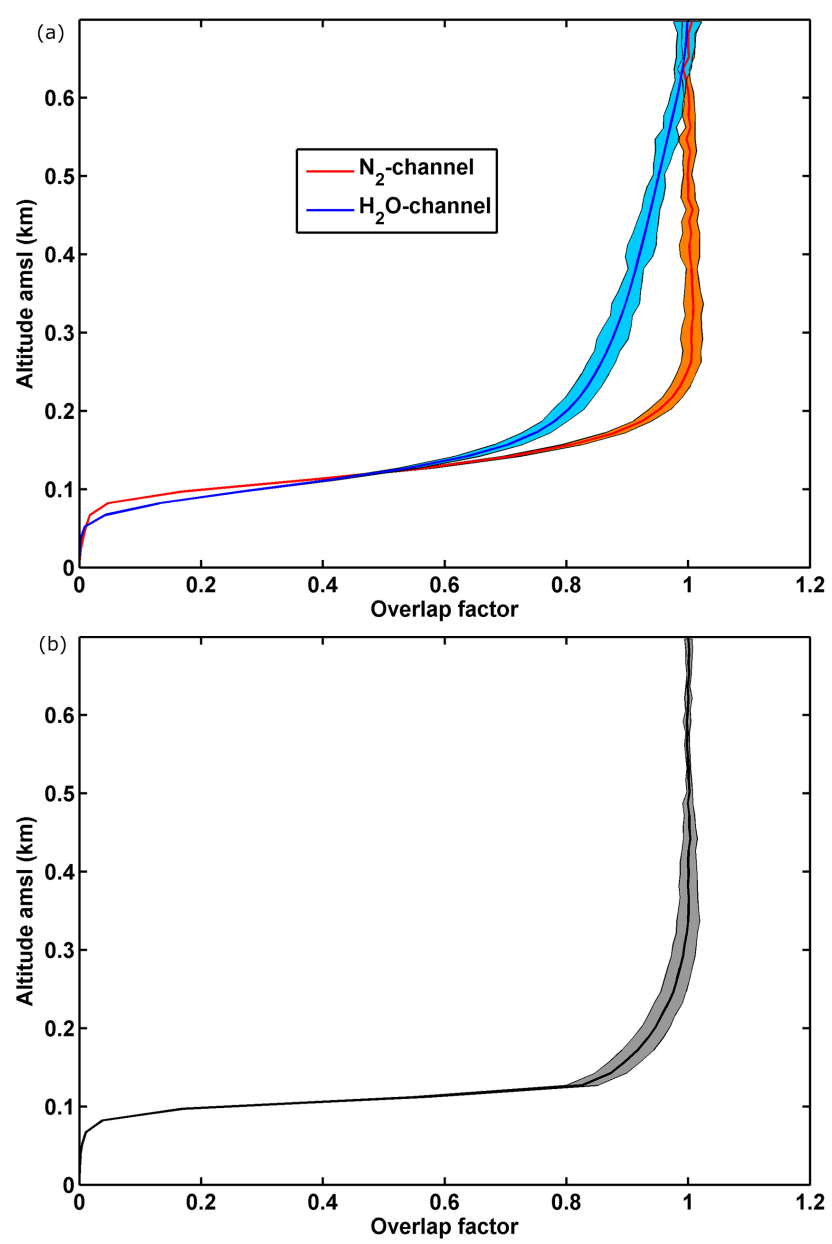

Figure 2. WALI overlap factors for the $\mathrm{N}_{2}$ and $\mathrm{H}_{2} \mathrm{O}$ channels (left) and elastic channel (right) as experimentally measured. The colored areas represent the standard deviations of the overlap factors.

\subsubsection{Water vapor mixing ratio}

The WVMR $\left(r_{\mathrm{H}}\right)$ is defined as the mass of water vapor divided by the mass of dry air in the same volume:

$r_{\mathrm{H}}(z)=\frac{N_{\mathrm{H}}(z)}{N_{\mathrm{N}}(z)} \cdot \frac{M_{\mathrm{H}}}{M_{\mathrm{N}}} \cdot r_{\mathrm{N}}$,

where $r_{\mathrm{N}}$ is the nitrogen mixing ratio that can be considered as a constant in the troposphere. $M_{\mathrm{H}}$ and $M_{\mathrm{N}}$ are the molar masses of water vapor and nitrogen, respectively. The WVMR can be directly derived from the ratio of the $\mathrm{H}_{2} \mathrm{O}$ channel and $\mathrm{N}_{2}$ channel as 


$$
\begin{aligned}
& r_{\mathrm{H}}(z)=K \cdot \xi(z) \cdot \frac{S_{\mathrm{H}}(z)}{S_{\mathrm{N}}(z)} \cdot \\
& \exp (\underbrace{-\left[\eta_{\mathrm{mN}}-\eta_{\mathrm{mH}}\right] \cdot \int_{Z_{\mathrm{G}}}^{Z} \alpha_{\mathrm{m}}\left(z^{\prime}\right) \cdot \mathrm{d} z^{\prime}}_{\text {Molecular contribution }}) \\
& \underbrace{-\int_{Z_{\mathrm{G}}}^{Z}\left[\eta_{\mathrm{aN}}\left(z^{\prime}\right)-\eta_{\mathrm{aH}}\left(z^{\prime}\right)\right] \cdot \alpha_{\mathrm{a}}\left(z^{\prime}\right) \cdot \mathrm{d} z^{\prime}}_{\text {Aerosol contribution }},
\end{aligned}
$$

where $K$ is the instrumental constant, expressed as

$$
K=\frac{C_{\mathrm{N}}}{C_{\mathrm{H}}} \cdot \frac{\sigma_{\mathrm{N}}^{\pi}}{\sigma_{\mathrm{H}}^{\pi}} \cdot \frac{M_{\mathrm{H}}}{M_{\mathrm{N}}} \cdot r_{\mathrm{N}} .
$$

The symbol $\xi$ is the ratio between the overlap factors of the $\mathrm{N}_{2}$-Raman and $\mathrm{H}_{2} \mathrm{O}$-Raman channels gradually approaching unity as a function of altitude and reaching 1.0 around $700 \mathrm{~m}$. Both $K$ and $\xi$ have to be assessed during a dedicated calibration procedure. The exponential term in Eq. (3) represents the atmospheric corrections associated with the spectrally dependent properties of the extinction coefficients of both molecules and aerosols.

\subsubsection{Aerosol optical properties}

The retrieval of the aerosol optical properties coupled to back-trajectory analyses can contribute to the identification of the air mass origin and to radiative balance studies above the Mediterranean Basin. These properties are obtained using the following procedure. Firstly, after the correction of the molecular contribution, the aerosol optical thickness (AOT) between a reference altitude $z_{0}$ and $z$ is derived from the $\mathrm{N}_{2}$ channel by means of (e.g., Royer et al., 2011)

$$
\begin{gathered}
\operatorname{AOT}\left(z_{0}, z\right)=\frac{1}{\left(1+\eta_{\mathrm{aN}}\right)} \cdot \mid \ln \left(\frac{S_{\mathrm{N}}\left(z_{0}\right)}{S_{\mathrm{N}}(z)} \cdot \frac{\beta_{\mathrm{N}}(z)}{\beta_{\mathrm{N}}\left(z_{0}\right)}\right. \\
\left.\cdot \exp \left(\left(1+\eta_{\mathrm{mN}}\right) \int_{z_{0}}^{z} \alpha_{\mathrm{m}}\left(z^{\prime}\right) \cdot \mathrm{d} z^{\prime}\right)\right) \mid
\end{gathered}
$$

The reference altitude $z_{0}$ can be taken in the upper or lower parts of the lidar profile. For this study, $z_{0}$ is chosen above the aerosol layers, i.e., between 4 and $6 \mathrm{~km}$ a.m.s.l. Hence, the aerosol backscatter coefficient $\beta_{\mathrm{a}}$ can be directly calculated as

$$
\begin{aligned}
& \beta_{\mathrm{a}}(z)=\beta_{\mathrm{E}}\left(z_{0}\right) \cdot S_{\mathrm{E}}(z) / S_{\mathrm{E}}\left(z_{0}\right) \\
& \cdot \exp \left(2 \cdot\left[\operatorname{sgn}\left(z-z_{0}\right) \cdot \operatorname{AOT}\left(z_{0}, z\right)+\int_{z_{0}}^{z} \alpha_{\mathrm{m}}\left(z^{\prime}\right) \cdot \mathrm{d} z^{\prime}\right]\right) \\
& -\beta_{\mathrm{m}}(z) .
\end{aligned}
$$

Secondly, the AOT can be used in two ways. The first one is via a regularization approach such as the Tikhonov regularization method (Tikhonov and Arsenin, 1977), from which the vertical profiles of LR and $\alpha_{\mathrm{a}}$ are derived (e.g., Royer et al., 2011) starting from the equation

$\operatorname{AOT}\left(z_{0}, z\right)=\left|\int_{z_{0}}^{z} \operatorname{LR}\left(z^{\prime}\right) \cdot \beta_{\mathrm{a}}\left(z^{\prime}\right) \cdot \mathrm{d} z^{\prime}\right|$.

The second one is via an iterative algorithm using the Klett (1985) approach (Chazette, 2003; Royer et al., 2011):

$\alpha_{\mathrm{a}}(z)=\overline{\mathrm{LR}}$

$$
\cdot\left(\frac{S_{\mathrm{E}}(z) Q(z)}{\frac{S_{\mathrm{E}}\left(z_{0}\right)}{\left(\beta_{\mathrm{m}}\left(z_{0}\right)+\beta_{\mathrm{a}}\left(z_{0}\right)\right)}+2 \cdot \overline{\mathrm{LR}} \cdot \int_{z}^{z_{0}} S_{\mathrm{E}}\left(z^{\prime}\right) Q\left(z^{\prime}\right) \mathrm{d} z^{\prime}}-\beta_{\mathrm{m}}(z)\right),
$$

where $Q$ is the correction related to the differential molecular optical thickness calculated from the vertical profile of the molecular scattering coefficient:

$$
Q(z)=\exp \left(2\left[k_{\mathrm{f}} \frac{3 \cdot \overline{\mathrm{LR}}}{8 \pi}-1\right] \int_{z}^{z_{0}} \alpha_{\mathrm{m}}\left(z^{\prime}\right) \mathrm{d} z^{\prime}\right) .
$$

The columnar mean lidar ratio $\overline{\mathrm{LR}}$ derived from this second approach corresponds to the value of $\operatorname{LR}(z)$ weighted by the aerosol extinction coefficient profile between $z$ and $z_{0}$.

The depolarization of the laser beam by aerosols is also a powerful tracer for the identification of the air mass origins. Taking into account that the channel transmissions are not pure in terms of polarization, the volume depolarization ratio (VDR) is expressed as (e.g., Chazette et al., 2012a)

$\operatorname{VDR}(z) \approx \frac{T_{1}^{/ /} \cdot S_{\mathrm{E} 2}(z)}{R_{\mathrm{c}} \cdot S_{\mathrm{E} 1}(z)}-\left(1-T_{1}^{/ /}\right) \cdot\left(1-T_{2}^{/ /}\right)$

$T_{1}^{/ /}$and $T_{2}^{/ /}$are the parallel transmissions of the total and cross-polarization channels. They were estimated before and after experiment in the laboratory on a specific optical bench (Chazette et al.., 2012a). The cross-calibration coefficient $R_{\mathrm{c}}$ can be assessed by normalizing the lidar signals obtained in a "clean" atmospheric volume with negligible aerosol content:

$$
R_{\mathrm{c}} \approx \frac{S_{\mathrm{E} 2}(z) \cdot T_{1}^{/ /}}{S_{\mathrm{E} 1}(z) \cdot\left[\left(1-T_{1}^{/ /}\right) \cdot\left(1-T_{2}^{/ /}\right)+\mathrm{VDR}_{\mathrm{m}}\right]},
$$

where the molecular volume depolarization ratio $\left(\mathrm{VDR}_{\mathrm{m}}\right)$ was taken equal to $0.3945 \%$ at $355 \mathrm{~nm}$ following Collis and Russel (1976). Therefore the particulate depolarization ratio (PDR) is computed from

$\operatorname{PDR}(z)=$

$$
\frac{\beta_{\mathrm{m}}(z) \cdot\left(\mathrm{VDR}_{\mathrm{m}}-\mathrm{VDR}(z)\right)-\beta_{\mathrm{a}}(z) \cdot \operatorname{VDR}(z) \cdot\left(1+\mathrm{VDR}_{\mathrm{m}}\right)}{\beta_{\mathrm{m}}(z) \cdot\left(\operatorname{VDR}(z)-\mathrm{VDR}_{\mathrm{m}}\right)-\beta_{\mathrm{a}}(z) \cdot\left(1+\mathrm{VDR}_{\mathrm{m}}\right)} .
$$




\subsection{Experimental sites}

To ensure its mobility, WALI was integrated into the LSCE Mobile Aerosol Station van (Chazette et al., 2005) also equipped with a VAISALA ${ }^{\mathrm{TM}} 200$ probe mounted on a mast at $\sim 10 \mathrm{~m}$ from the surface, which measures the air pressure, temperature and relative humidity. Different experimental sites have been considered to calibrate and test WALI under field conditions. The first one is an area $\sim 30 \mathrm{~km}$ south of Paris $\left(48^{\circ} 42^{\prime} 23^{\prime \prime} \mathrm{N}\right.$ and $\left.2^{\circ} 13^{\prime} 22^{\prime \prime} \mathrm{E}\right)$. It is located less than $20 \mathrm{~km}$ south-southeast of the Trappes meteorological station where rawinsoundings were performed twice a day. The second one is at Candillargues near Montpellier $\left(43^{\circ} 37^{\prime} 14^{\prime \prime} \mathrm{N}\right.$ and $4^{\circ} 4^{\prime} 11^{\prime \prime} \mathrm{E}$ ) in the south of France, close to the Mediterranean coast. This site was selected for the opportunity of launching a radiosonde during the lidar measurements without constraint from the air traffic. The third site is situated on the Balearic island of Menorca (Spain) selected to conduct the HyMeX fall campaign in 2012 and the ChArMEx summer campaign in 2013. The aim was to document the water vapor and aerosol vertical distribution before the air masses reach the Spanish and French coasts (Fig. 3). The lidar van was operated from a site close to Ciutadella (western part of Menorca, $39^{\circ} 59^{\prime} 07^{\prime \prime} \mathrm{N}$ and $3^{\circ} 50^{\prime} 13^{\prime \prime} \mathrm{E}$ ) for HyMeX, and from a site south of Mahon international airport (eastern part of Menorca, 39 $49^{\prime} 33^{\prime \prime} \mathrm{N}$ and $4^{\circ} 12^{\prime} 29^{\prime \prime} \mathrm{E}$ ) for ChArMEx. Rawinsoundings were performed from Palma de Majorca (Majorca), $\sim 100 \mathrm{~km}$ southwest from the lidar location. A dedicated calibration flight was also performed over Mahon in the eastern part of Menorca, at about $40 \mathrm{~km}$ east of Ciutadella. The main experimental period discussed here took place between 10 September and 30 October 2012 during the HyMeX fall campaign.

\section{Lidar calibration to retrieve the WVMR}

As previously discussed, the vertical WVMR profile is retrieved using the ratio between the $\mathrm{H}_{2} \mathrm{O}-$ Raman and $\mathrm{N}_{2}$ Raman return signals. Nevertheless, this retrieval is subject to the prior assessment of both the calibration constant $K$ and the overlap factor ratio $\xi$. The calibration was performed in comparison with a simultaneous vertical sounding using a well-qualified meteorological probe. $K$ is first assessed using the upper part of the rawinsounding profile and $\xi$ is then retrieved from the lower part (below $0.8 \mathrm{~km}$ a.m.s.l.). The unknown calibration coefficients were derived in a least-squares sense by minimizing the differences between the rawinsonde and the lidar profiles. Note that for comparison, Vaughan et al. (1988) performed a calibration of their Raman lidar on an optical bench leading to a final precision of $12 \%$ on the WVMR.

For the same purpose, atmospheric water vapor profiles were monitored in the south of Paris, in the southeast of France, and at Menorca before, during and after the HyMeX

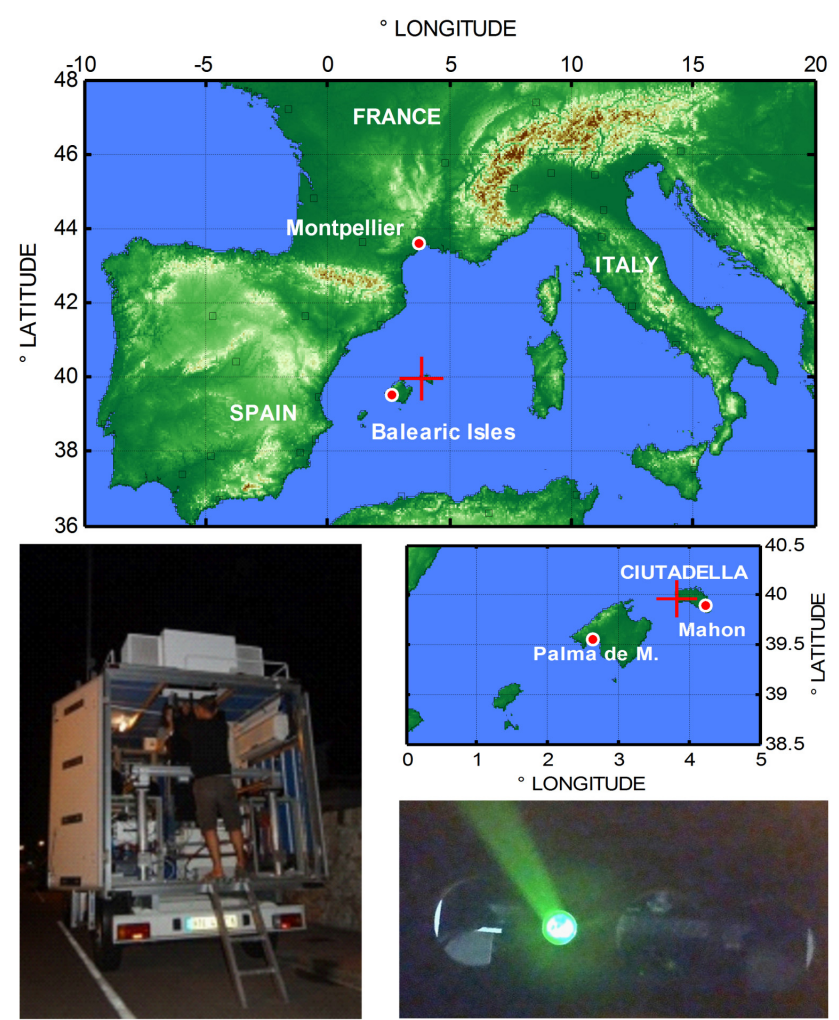

Figure 3. Southern experimental sites selected for both the HyMeX and the ChArMEx campaigns. The ground-based lidar van is shown on the bottom left. The main experimental sites are indicated on the map.

IODA-MED campaign of September-October 2012. The calibration procedure was conducted following three consecutive steps:

1. Lidar-derived WVMR profiles were compared with specific nighttime rawinsoundings carried out by MeteoFrance on 1 September and 27 October 2012 close to Paris and Montpellier, respectively. Hence, both $K$ and $\xi$ were assessed.

2. Due to the difference of photomultiplier $\mathrm{HV}$ used during nighttime (950 and $1000 \mathrm{~V}$ for the $\mathrm{N}_{2}$ and $\mathrm{H}_{2} \mathrm{O}$ channels, respectively) and daytime, a specific calibration function was derived to allow continuity between the lidar measurements performed during nighttime and daytime, as $K$ is changing with $\mathrm{HV}$.

3. Independent rawinsoundings were used to validate the previous calibrations using daytime and nighttime measurements performed from airborne platforms equipped with VAISALA ${ }^{\mathrm{TM}}$ probes. These checks were performed before, during and after the campaign. Note that the WALI final vertical resolution was fixed to $50 \mathrm{~m}$ for this calibration exercise. 


\subsection{Calibration}

The rawinsounding performed near Montpellier was very close to the lidar van (launch at a distance of $\sim 100 \mathrm{~m}$ ), and is thus considered to be the most relevant means to calibrate the lidar. It was carried out on 30 October 2012 during nighttime at 22:00 local time (LT). The result after calibration with $K=0.066$ is given in Fig. 4. The presence of clouds, highlighted on the elastic range-corrected lidar signal $S_{355}$, prevents us from verifying the agreement between the instruments above $1.6 \mathrm{~km}$ a.m.s.l. The standard deviation (SD) between the lidar- and rawinsounding-derived WVMR is $0.13 \mathrm{~g} \mathrm{~kg}^{-1}(\sim 2.3 \%)$. The rawinsounding station of Trappes has also been used to test the calibration with the same value of $K=0.066$ for a lidar measurement performed in the Paris area (Palaiseau) $\sim 19 \mathrm{~km}$ downwind from the sounding station. The agreement is very good below $2 \mathrm{~km}$ a.m.s.l., with a SD of $0.2 \mathrm{~g} \mathrm{~kg}^{-1}$. Above $2 \mathrm{~km}$ the discrepancy increases, with a SD close to $0.5 \mathrm{~g} \mathrm{~kg}^{-1}$. The presence of mid-altitude clouds can explain the differences between lidar and rawinsounding above $2.5 \mathrm{~km}$ a.m.s.l.

\subsection{High-voltage variation during daytime}

The diurnal evolution of the calibration coefficient $K$ was measured by two specific experiments over Menorca during fall 2012. It is given in Fig. 5 against the $\mathrm{N}_{2}$ - and $\mathrm{H}_{2} \mathrm{O}$ Raman channels. During daytime the HVs were close to 850 and $650 \mathrm{~V}$ for the $\mathrm{N}_{2}-$ and $\mathrm{H}_{2} \mathrm{O}-\mathrm{Raman}$ channels, respectively. With such voltage values, $K$ increases significantly to reach $\sim 1$. This calibration has been tested by measuring in the same air mass for HVs from 650 to $1000 \mathrm{~V}$. Moreover, two areas (Menorca and Paris) with different WVMR have been considered, as shown in Fig. 6. The results are in good agreement, with a SD of $\sim 0.8$ and $\sim 0.5 \mathrm{~g} \mathrm{~kg}^{-1}$ for Menorca and Paris, respectively, between 0.2 and $1 \mathrm{~km}$ a.m.s.l. Note that the use of lower HVs leads to a decrease in the accessible altitude range because a lower PMT gain (chosen to avoid saturation by the sky background) decreases the signal-tonoise ratio.

\subsection{Validation using independent rawinsoundings}

The validation of the previous calibration was carried out using in situ measurements from balloon and aircraft. Figure 7 gives comparisons between WVMR retrieved from lidar and rawinsounding over the same previous sites of the Paris area before and several months after the IODA-MED campaign. The first (second) comparison is during nighttime (daytime). On 5 September 2012, the lidar and rawinsounding comparison leads to a SD of $0.83 \mathrm{~g} \mathrm{~kg}^{-1}$ for the WVMR profile between 0.3 and $5 \mathrm{~km}$ a.m.s.l. The larger discrepancies are mainly due to the air mass variability in the lower part of the profile. The agreement is significantly better on 19 February 2013, when measurements were performed during daytime.
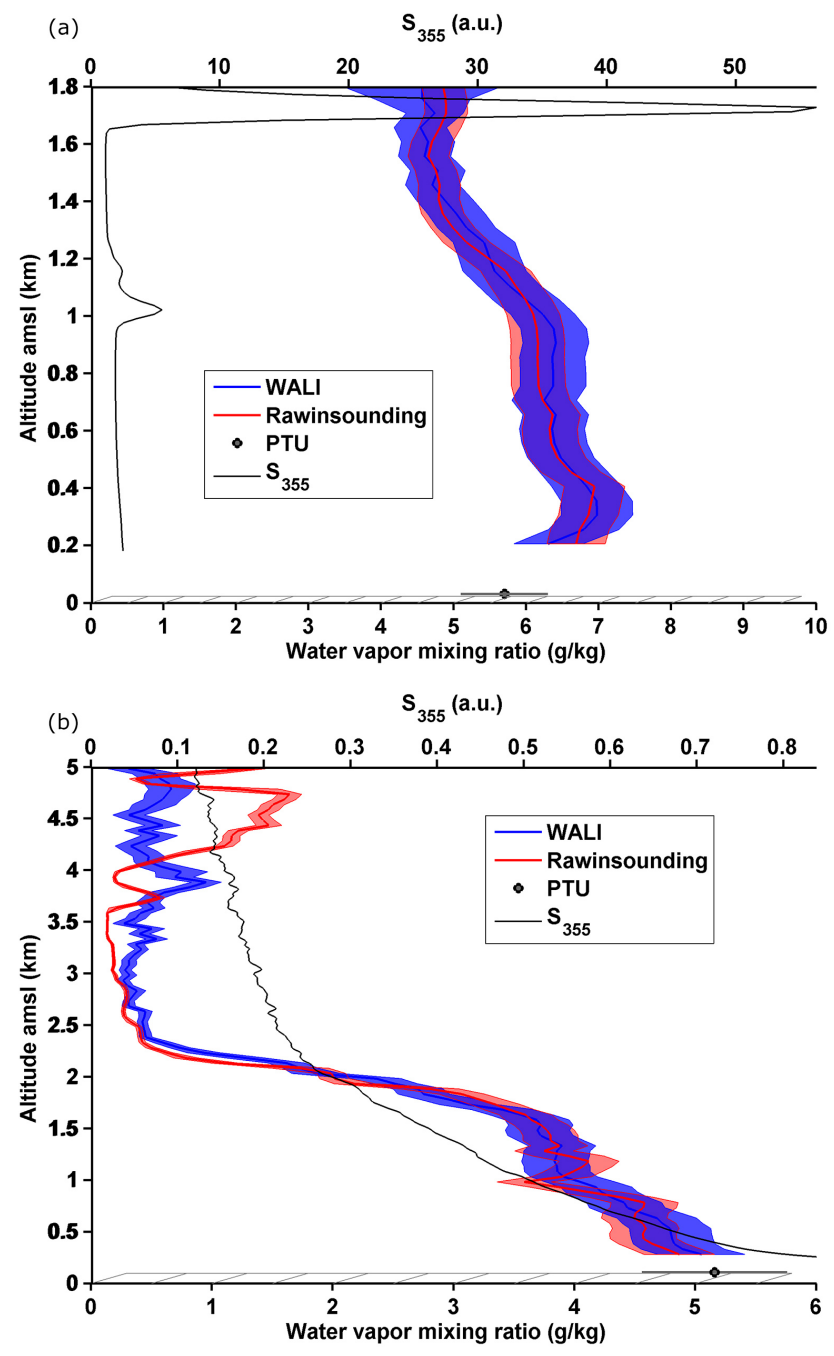

Figure 4. WALI water vapor mixing ratio calibration by comparison to rawinsounding: in Montpellier on 30 October 2012, 22:00 LT (top), and in Palaiseau (Paris area) on 1 September 2012, 01:00 LT (bottom). The red (blue) areas give the standard deviations around the mean value derived from the rawinsoundings (lidar). PTU stands for the ground-based measurements at $\sim 10 \mathrm{~m}$ above the surface. The range-corrected elastic lidar signal $S_{355}$ is also plotted in black.

The SD is equal to $0.29 \mathrm{~g} \mathrm{~kg}^{-1}$ for altitudes between $\sim 0.5$ and $1.2 \mathrm{~km}$.

A specific flight was performed above Mahon on 27 October 2012, between 08:30 and 09:30 LT. The meteorological probe fixed on the plane was a VAISALA ${ }^{\mathrm{TM}}$ PTB110-Veriteq SP2000, which delivers the thermodynamic temperature with an uncertainty of $0.15 \mathrm{~K}$, the pressure with an uncertainty of $0.6 \mathrm{hPa}$ and the relative humidity with a relative uncertainty of $5 \%$ for the atmospheric conditions encountered in the low and middle troposphere. This leads to an absolute uncertainty of $0.67 \mathrm{~g} \mathrm{~kg}^{-1}$ on the WVMR. As shown in Fig. 8, when compared to the lidar-derived WVMR, the SD is $0.55 \mathrm{~g} \mathrm{~kg}^{-1}$ for altitudes between 0.2 and $1.2 \mathrm{~km}$ a.m.s.1., which is close 


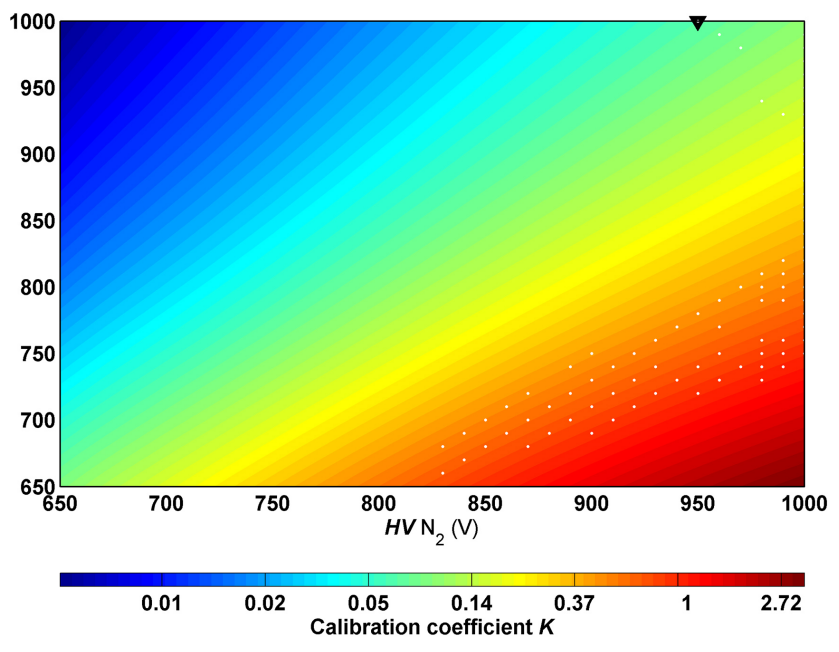

Figure 5. Photomultiplier high-voltage (HV)- dependent calibration coefficient $K$ with respect to $\mathrm{N}_{2}$ channel and $\mathrm{H}_{2} \mathrm{O}$ channel HVs. The black triangle indicates the usual nighttime setup. The white dots represent the automatically selected HVs during daytime.

to the error bars. Note that for the lidar, the SD is also due to the atmospheric variability during the diurnal averaging time of $1 \mathrm{~h}$. Nighttime comparison with the rawinsounding of Palma de Majorca leads to a similar SD of $0.48 \mathrm{~g} \mathrm{~kg}^{-1}$. Figure 8 also includes a comparison to operational modeling. The first output is from ECMWF (European Centre for Medium-Range Weather Forecasts, www.ecmwf.int) analyses at a horizontal resolution of $0.5^{\circ}$. The nine closest grid points from Ciutadella have been considered, showing that the WVMR below $2 \mathrm{~km}$ is not fluctuating much, with a SD of $0.22 \mathrm{~g} \mathrm{~kg}^{-1}$. The second model is AROME-WMED, for which the WVMR forecast has been extracted above the ground-based lidar location. AROME-WMED is a mesoscale model based on a three-dimensional variational data assimilation system with a horizontal resolution of $2.5 \mathrm{~km}$, centered over the western part of the Mediterranean Basin for real-time and case-study uses, and was developed for the preparation of the experimental HyMeX special observation period. It is derived from the operational version of the AROME model (Seity et al., 2011), which is centered over France. Lateral boundary conditions are provided by the global model ARPEGE (Action de Recherche Petite Echelle Grande Echelle). As shown in Fig. 8 and for the same range of altitudes from 0.2 to $1.2 \mathrm{~km}$ a.m.s.l., the comparison of lidar-derived WVMR for this specific case leads to a SD of 0.51 and $0.81 \mathrm{~g} \mathrm{~kg}^{-1}$ for ECMWF and AROME-WMED, respectively.

\section{Error estimation}

The different sources of uncertainty playing a major role in both the WVMR and the aerosol optical properties retrievals
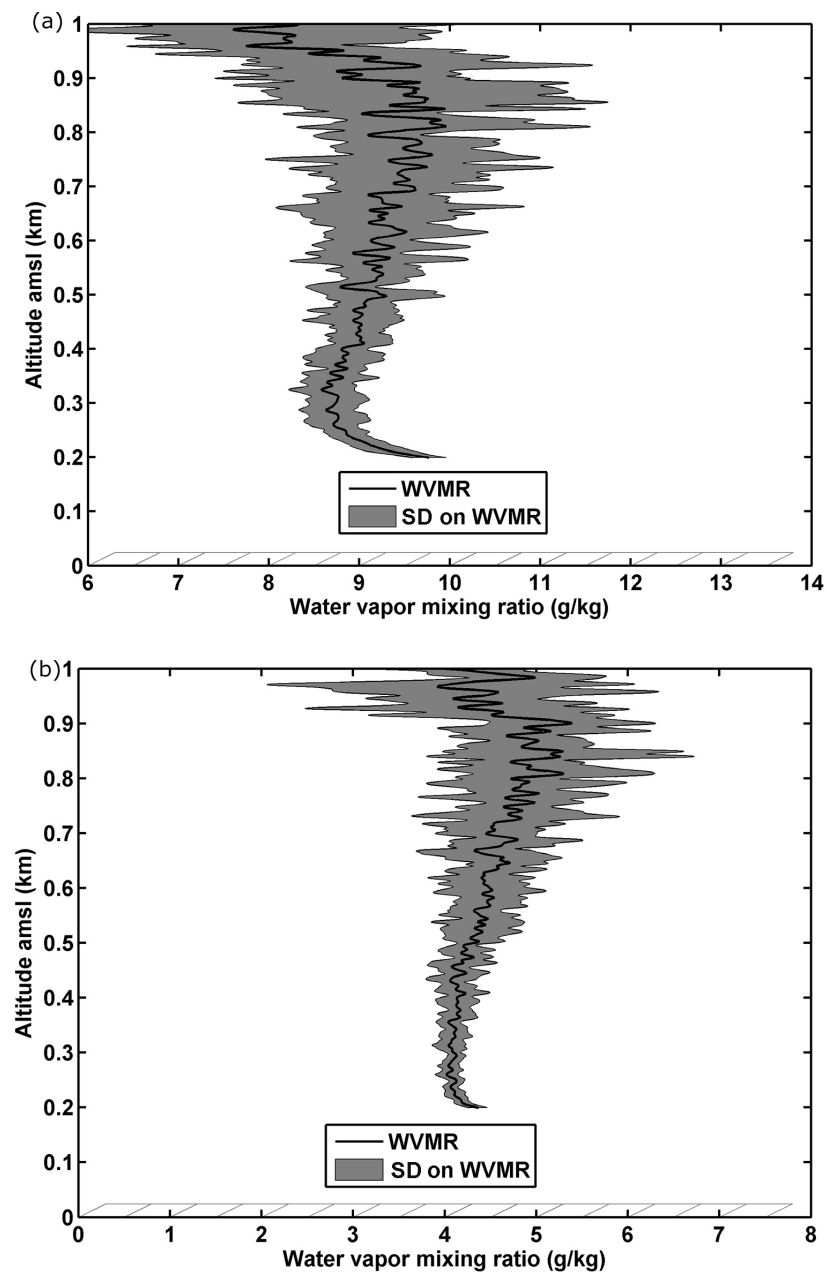

Figure 6. Test of the water vapor mixing ratio (WVMR) calibration for high voltages (HV) varying between 650 and $1000 \mathrm{~V}$ over the Menorca site (on 21 October 2012, from 20:00 to 20:30 LT) (left) and the Paris area (8 November 2012, from 17:45 to 18:15 LT). Both the mean value and the standard deviation ( $\mathrm{SD}$, gray area) computed on the WVMR retrieval are derived from lidar profiles associated with the different HVs.

will be analyzed in this section. For the latter, we will consider the results already published by Chazette et al. (2012b) discussing the methodology developed for the same type of lidar.

The uncertainties in the determination of the WVMR are related to three main sources: (i) the shot noise characterized by the signal-to-noise ratio $\left(\mathrm{SNR}_{\lambda}\right)$ of the lidar system, (ii) the calibration related to rawinsoundings, and (iii) the molecular and aerosol contributions. Up to the first order, the relative uncertainty $\varepsilon_{\mathrm{H}}$ on $r_{\mathrm{H}}$ is then given by

$\varepsilon_{\mathrm{H}} \approx \sqrt{\underbrace{\frac{1}{\mathrm{SNR}_{\mathrm{N}}^{2}}+\frac{1}{\mathrm{SNR}_{\mathrm{H}}^{2}}}_{\text {Shot noise }}+\underbrace{\varepsilon_{K}^{2}+\varepsilon_{\xi}^{2}+\varepsilon_{\mathrm{HV}}^{2}}_{\text {Calibration }}+\underbrace{\varepsilon_{\mathrm{m}}^{2}+\varepsilon_{\mathrm{a}}^{2}}_{\text {Atmosphere }}}$, 
(a)

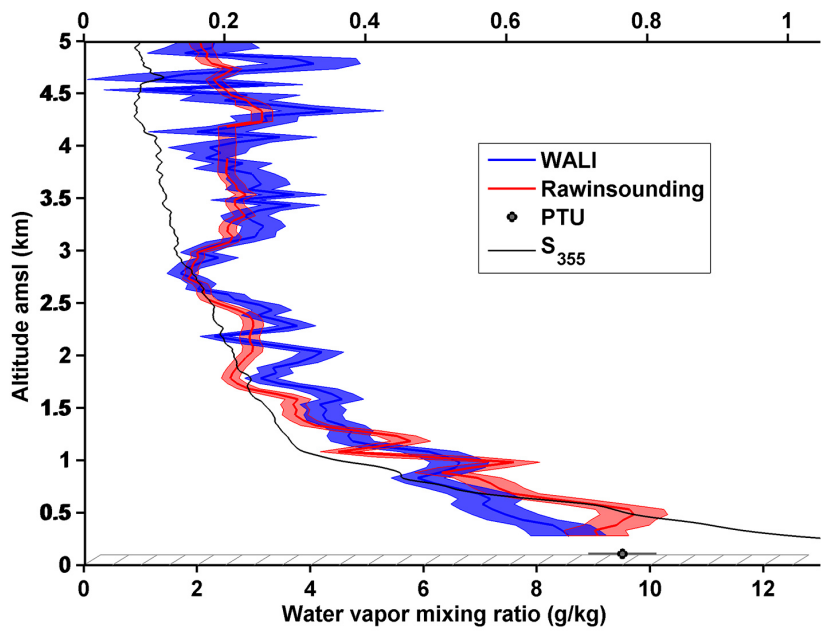

(b)

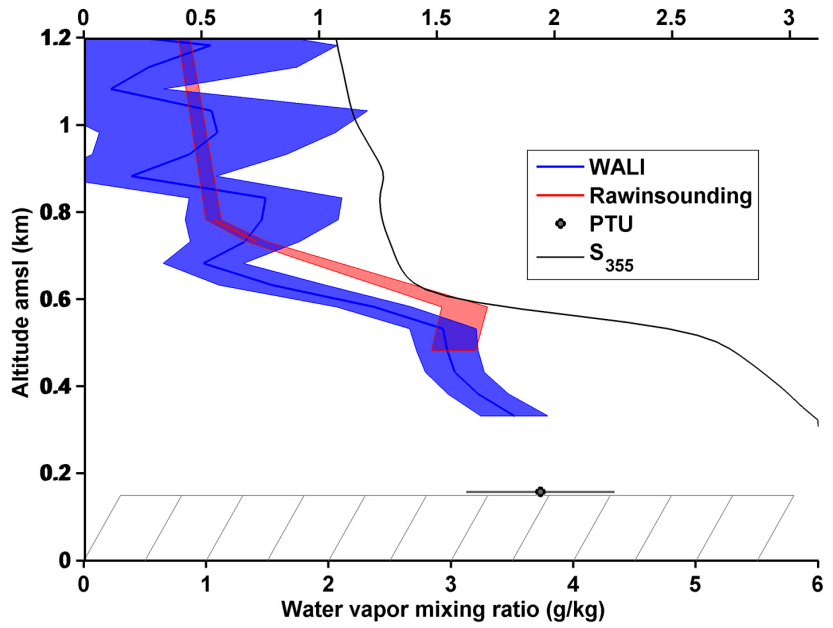

Figure 7. Validation of the calibration of WALI by comparing lidarderived water vapor mixing ratio (WVMR) measurements to rawinsoundings in the Paris area before the IODA-MED experiment (5 September 2012, 00:50-01:15 LT (top)) and after it (19 February 2013, 12:30-13:00 LT (bottom)). The red (blue) areas indicate the standard deviations around the WVMR mean value derived from the rawinsoundings (lidar). PTU stands for the ground-based measurements at $\sim 10 \mathrm{~m}$ above the surface. The range-corrected elastic lidar signal $S_{355}$ is also plotted in black.

where $\varepsilon_{K}, \varepsilon_{\xi}$ and $\varepsilon_{\mathrm{HV}}$ are the relative uncertainties due to the calibration constant $K$, the overlap factors and the uncertainty resulting from the HV variation, respectively. The relative uncertainty associated with the spectral-dependent properties of the extinction for molecules (aerosols) is given by $\varepsilon_{\mathrm{m}}\left(\varepsilon_{\mathrm{a}}\right)$.

\subsection{Shot noise}

An accurate assessment of the shot noise contribution requires an accurate characterization of the SNR. During night-

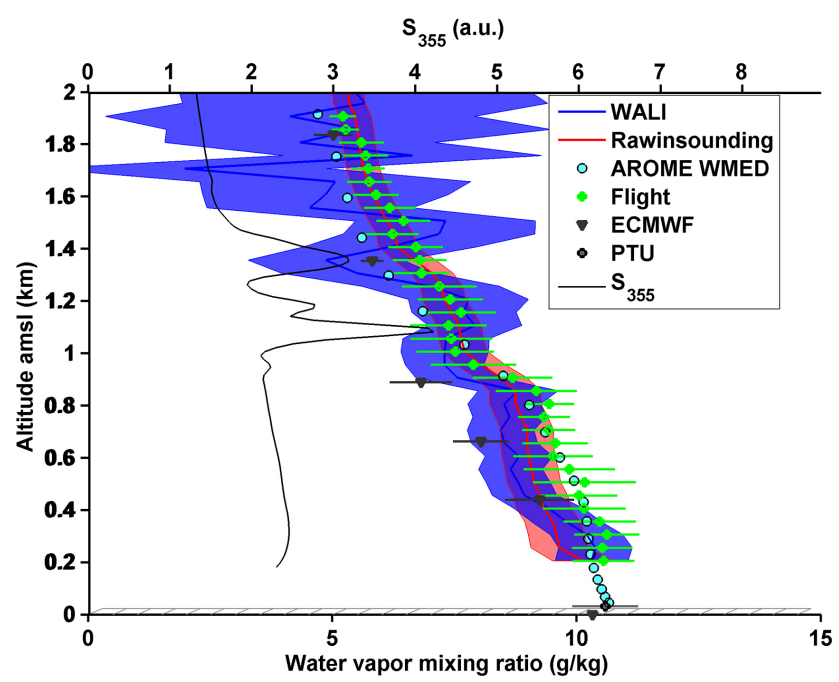

Figure 8. Comparison of lidar-derived water vapor mixing ratio (WVMR) in Ciutadella to airborne in situ measurements during a flight over Mahon (with green error bars), Palma rawinsounding, ECMWF (with the standard deviation for the nine closest modeled profiles from the lidar location) and AROME-WMED model outputs on 27 October 2012, 08:30 to 09:30 LT. The red (blue) areas indicate the standard deviations around the WVMR mean value derived from the rawinsoundings (lidar). PTU stands for the ground-based measurements at $\sim 10 \mathrm{~m}$ above the surface. The range-corrected elastic lidar signal $S_{355}$ is also plotted in black.

time such assessment is easier because the photon counting mode is active. In that mode, the associated standard deviation is the square root of the returned signal (Measures, 1984). An example is given in Fig. 9 for a lidar signal acquired during the night of 19 October 2012 over Menorca with a vertical resolution of $15 \mathrm{~m}$. The SNR is assessed for a lidar profile derived from an average over 1000 laser shots. The SNR for a larger number of laser shots $p$ can be easily calculated knowing that it is proportional to $\sqrt{p}$. For a lidar signal averaged over $20 \mathrm{~min}$ (20000 laser shots) and using a Monte Carlo approach as in Royer et al. (2011), the uncertainty on the WVMR has been assessed as $\sim 0.08$ (0.32) $\mathrm{g} \mathrm{kg}^{-1}$ between 0 and $2 \mathrm{~km}(2$ and $5 \mathrm{~km})$ a.m.s.l. Figure 10 shows an example obtained during the same day for a representative WVMR vertical profile. Such uncertainties are slightly lower than the deviations measured during the intercomparison between lidar measurements and rawinsoundings.

\subsection{Calibration}

The relative uncertainty on the assessment of the overlap factor $F$ is close to $3 \%$ and comparable to the previous assessment of $5 \%$ performed by Chazette (2003) when using the same approach. This leads to a relative uncertainty $\varepsilon \xi \sim$ $4 \%$ for altitudes between 0.3 and $0.8 \mathrm{~km}$ a.m.s.l. The accuracy and precision of the calibration constant $K$ are closely 


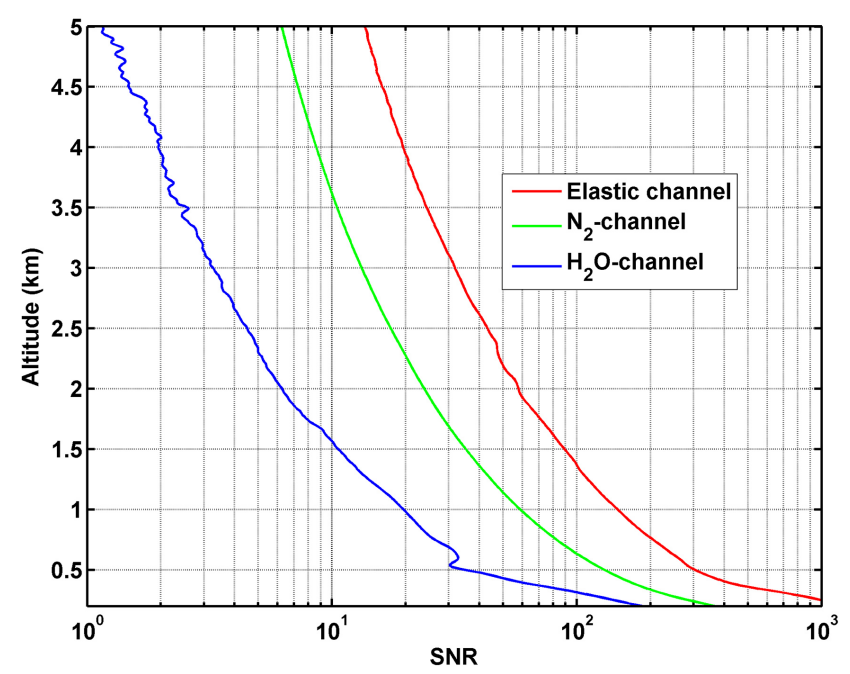

Figure 9. WALI signal-to-noise ratio (SNR) as a function of altitude for 3 channels (elastic, $\mathrm{N}_{2}$-Raman and $\mathrm{H}_{2} \mathrm{O}$-Raman) for a lidar profile derived from an average of 1000 shots obtained on 19 October 2012 during nighttime over Menorca.

related to the rawinsounding error that is directly linked to the type of radiosonde used for the rawinsounding. It is not easy to obtain such information from meteorological services; fortunately some publications give the relative uncertainty for some meteorological probes (e.g., Bock and Nuret, 2009). The rawinsoundings performed over Palma de Majorca used VAISALA ${ }^{\mathrm{TM}}$ RS92 probes. A discussion on various VAISALA ${ }^{\mathrm{TM}}$ probes was presented by Agusti-Panareda et al. (2009) following the African Monsoon Multidisciplinary Analysis (AMMA) field experiment in 2006, when numerous rawinsoundings were performed. They used the results of the WMO rawinsounding intercomparison experiment (Nash et al., 2005) and the correction used by Ciesielski et al. (2003) for modeling applications. Such a correction has its own uncertainties, as explained by Wang and Zhang (2008); Wang et al. (2002), because it does not take into account the solar heating effect, which affects the measurements during daytime. Moreover, the accuracy is affected by wet and dry biases. The magnitude of the humidity correction is up to $5 \%$ in the lower troposphere but can reach $20 \%$ in the upper troposphere. Ferrare et al. (2006) claim an accuracy of $2-3 \%$ with a precision of $2 \%$. Such results have been confirmed by Fujiwara et al. (2003) and Bock and Nuret (2009) for VAISALA ${ }^{\mathrm{TM}}$ RS80 and RS92 probes. Accounting for all these considerations, we consider here that the relative error on the rawinsounding-derived WVMR is about $6 \%$ between 0 and $5 \mathrm{~km}$ a.m.s.l. From the SD of the differences between the lidar- and rawinsounding-derived WVMR, the calibration error is estimated to be $\varepsilon_{K} \sim 6.5 \%$.

During daytime the effect of the HV variation has to be considered. The uncertainty here is mainly due to the atmospheric variability during the $\mathrm{HV}$ changes $(\sim 30 \mathrm{~min})$. For

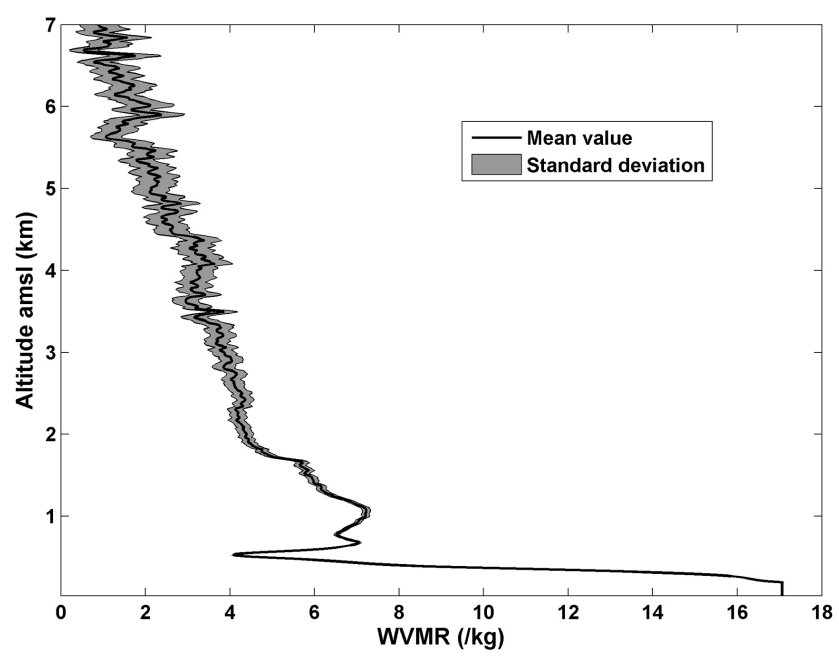

Figure 10. WALI-derived water vapor mixing ratio (WVMR) profile (black) and its associated standard deviation (gray) averaged over $20 \mathrm{~min}$ (20000 laser shots) during the night of 19 October 2012 over Menorca.

mean lidar profiles of 1000 laser shots (Fig. 6), the additional relative error is high $(\sim 10 \%)$. During daytime the number of laser shots thus has to be increased $(60000$ for $1 \mathrm{~h}$ integration) and the corresponding uncertainty should decrease (if all other disturbing parameters are stable), but it is difficult to quantify it. The easiest approach is to compare the lidar-derived WVMR to the one retrieved from daytime rawinsounding as shown in Sect. 3. The calibration error is then around $7 \%$.

\subsection{Molecules and aerosols spectral dependencies}

This third source of uncertainty is negligible compared to the others. Indeed, the residual molecular contribution can easily be corrected using a climatological model as in Chazette et al. (2003), leading to a very low uncertainty, i.e., less than $10^{-3} \mathrm{~g} \mathrm{~kg}^{-1}\left(0.3 \mathrm{~g} \mathrm{~kg}^{-1}\right.$ when not corrected). The presence of aerosols leads to an error on $r_{\mathrm{H}}$ close to $0.01 \mathrm{~g} \mathrm{~kg}^{-1}$ (for $A=1$ ). Nevertheless, this contribution can be corrected after the retrieval of the AOT from the $\mathrm{N}_{2}$-Raman channel.

\subsection{Synthesis on the WVMR error}

Accounting for the major sources of uncertainty, the relative VWMR error can be established for three different altitude ranges. During nighttime and for a temporal integration of $20 \mathrm{~min}$ (20000 laser shots), the relative uncertainty on the WVMR is $\sim 8 \%$ within the first kilometer $(0-0.8 \mathrm{~km}$ a.m.s.l.). It reaches $11 \%$ between 2 and $5 \mathrm{~km}$ a.m.s.l. The smallest relative uncertainty is between 0.8 and $2 \mathrm{~km}$ a.m.s.l., with a value of $\sim 7 \%$. Of course, the transitions are gradual and these uncertainties may change depending on the presence of more-or-less moist air masses in the middle troposphere. During daytime, the same relative 
uncertainties can be reached in the first kilometer but with $1 \mathrm{~h}$ integration time. For operational purposes, the uncertainty on the WVMR can be calculated for each averaged profile knowing the SNR for both the $\mathrm{N}_{2}$ and $\mathrm{H}_{2} \mathrm{O}$ channels. The main error source that could be reduced is the one due to the calibration, which is entirely dependent on both the reference rawinsounding measurement accuracy and precision.

\subsection{Aerosol optical properties}

Uncertainties on the retrieval of aerosol optical properties from similar detection channels have already been extensively discussed in the scientific literature (e.g., Chazette et al., 2010; Royer et al., 2011). For SNR > 20 as encountered with WALI, the relative uncertainty on the LR is $\sim 5 \%$ $(\sim 10 \%)$ during nighttime (daytime). The relative uncertainty on the VDR and PDR is close to $10 \%$ for the encountered AOT $>0.2$. The relative uncertainty on the AOT is less than $2 \%$.

\section{A case study analysis during the HyMeX campaign}

WALI was operated during the 2012 fall campaign of the HyMeX program (Special Observing Period 1), between 17 September and 27 October. After presenting the lidar calibration and the assessment of the different error sources, we will present a study of a typical meteorological situation using a synergy between the WVMR and aerosols lidar measurements. As shown in Fig. 11, an intense dust aerosol event was observed from 17 to 20 October. The VDR highlights two maxima, one on 18 October and the other on 19 October. This event has been sampled to follow the time evolution of the aerosol layer. The different time periods considered are given in Table 2 with the corresponding dust layers and their main optical characteristics. The values of the WVMR are also given, showing a strong link between dust layers and significant water vapor contents.

Such an experiment uses the entire capability of the lidar but needs complementary information. Hence, additional modeling results have been used. Air mass back trajectories have been computed to determine the corresponding transport routes (Fig. 12) using the NOAA Hybrid Single Particle Lagrangian Integrated Trajectory (HYSPLIT) model (Draxler and Rolph, 2003) with 3-hourly archived meteorological data provided by the US National Centers for Environmental Prediction (NCEP) Global Data Assimilation System (GDAS) at the horizontal resolution of $0.5^{\circ}$. The altitude of the trajectory starting point was selected primarily from the lidar/in situ observation of aerosol layer heights. The WVMR along the air mass trajectory was retrieved using the HYSPLIT model, which calculates the main meteorological parameters (i.e., temperature, relative humidity, pressure) along its trajectories. Note that the WVMRs given by the HYSPLIT model have been found to be in good agree-
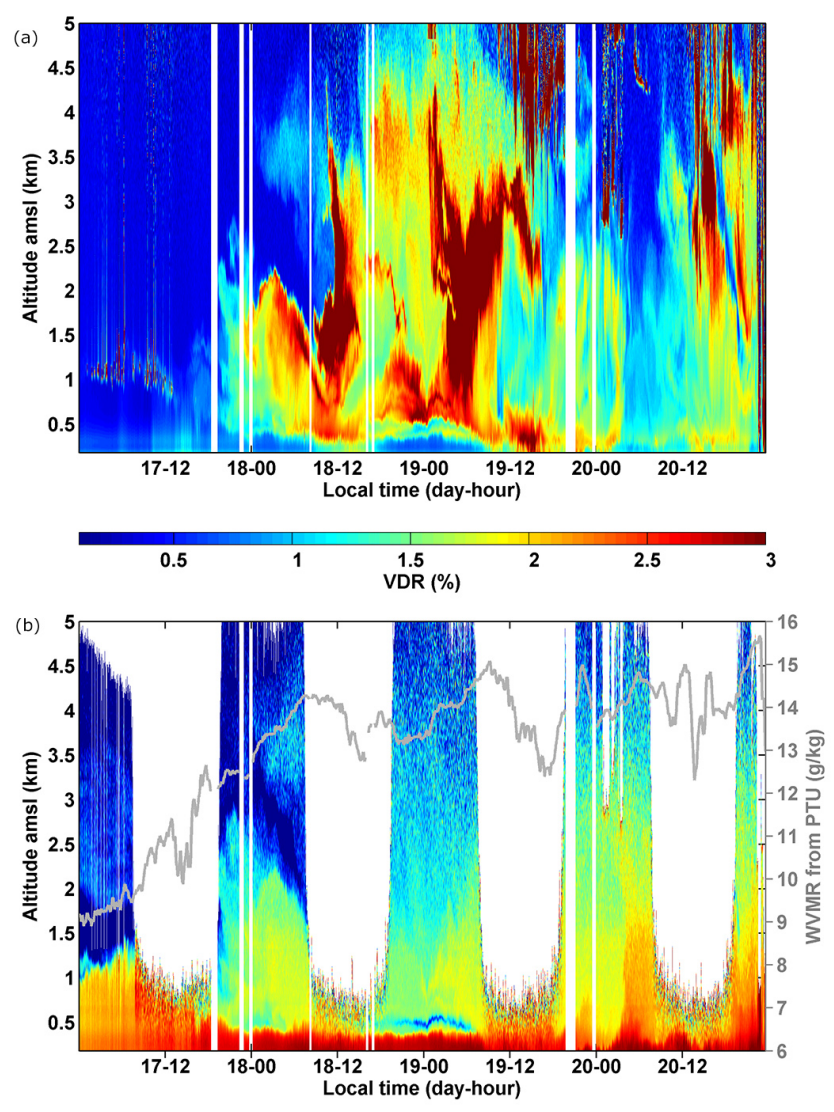

$\begin{array}{lllllllllll}2.23 & 2.72 & 3.32 & 4.06 & 4.95 & 6.05 & 7.39 & 9.03 & 11.02 & 13.46 & 16.44\end{array}$

Figure 11. WALI lidar-derived volume depolarization ratio (VDR, upper panel) and water vapor mixing ratio (WVMR, lower panel) from 17 October to 20 October over Menorca. The gray solid line in the lower graph represents ground-based WVMR measurements from a meteorological probe at $\sim 10 \mathrm{~m}$ above the surface (right axis).

ment with those of balloon-borne data observed at an adjacent rawinsounding site over Asia (Yoon et al., 2006). The outputs of the ECMWF reanalysis (http://www.ecmwf.int) have also been considered for illustrating the horizontal wind field.

Before the dust event, winds in the lower troposphere are southwesterly with low speeds on the order of $2-5 \mathrm{~m} \mathrm{~s}^{-1}$ (Fig. 13). They are associated with a low-pressure area situated in the southwestern part of Ireland. Synoptic winds are transporting the aerosol layer above the marine boundary layer (MBL) (Fig. 14) from the Spanish coast. In this layer, the mean LR (PDR) is $\sim 77 \mathrm{sr}(1 \%)$, as can be expected for this type of pollution particles. The VDR is close to the molecular contribution on the entire sampled atmospheric column (Fig. 14): no desert dust aerosol is present. The higher values of the WVMR are located in the MBL $\left(\sim 9-10 \mathrm{~g} \mathrm{~kg}^{-1}\right)$ with a top altitude remaining below $0.5 \mathrm{~km}$ a.m.s.l. during the entire the experiment. A wet 
a)
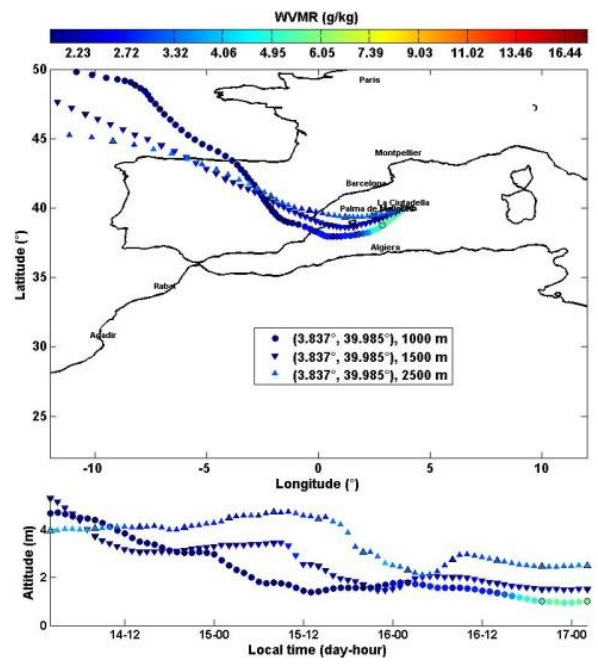

c)

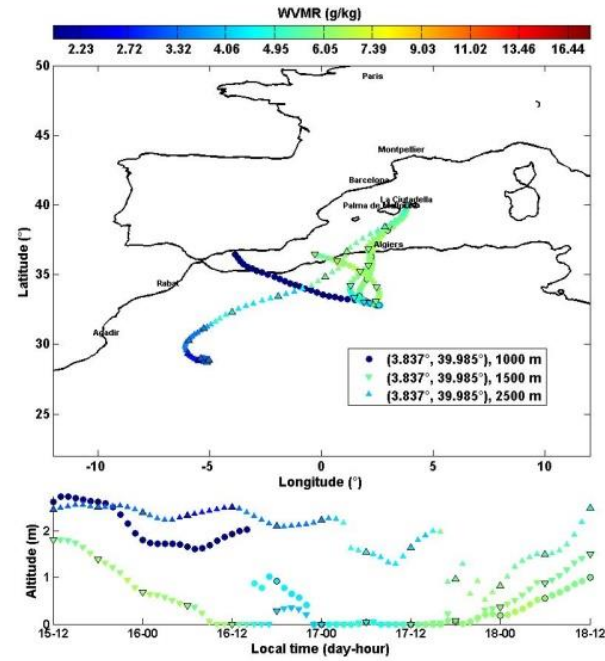

e)

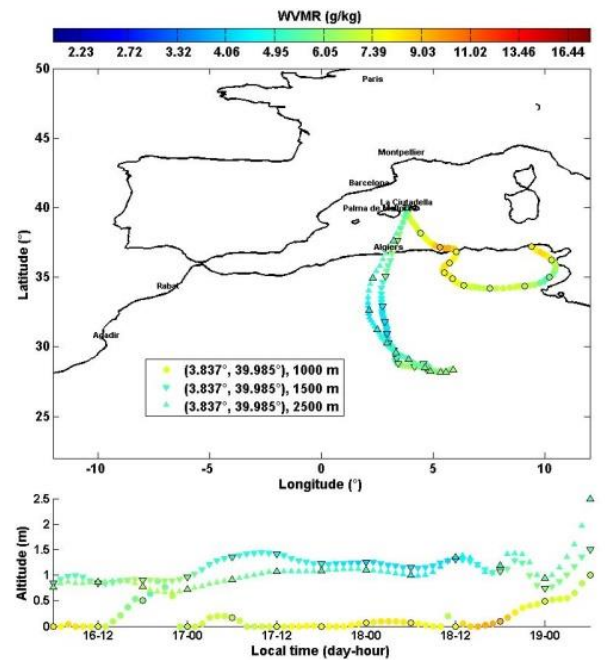

b)
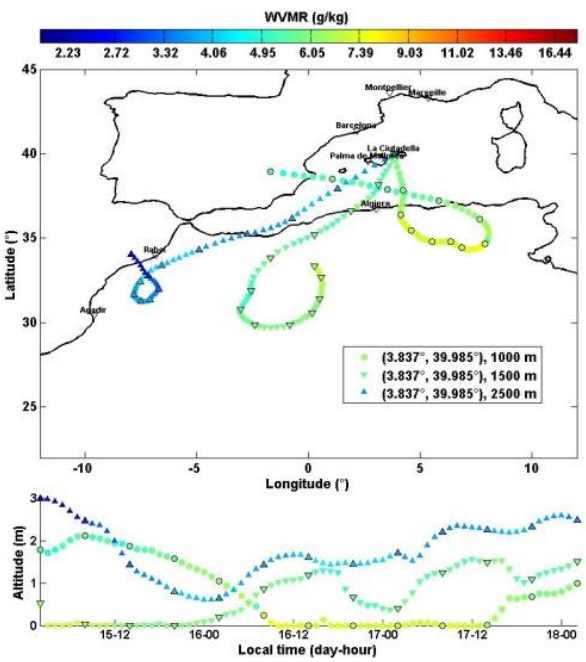

d)
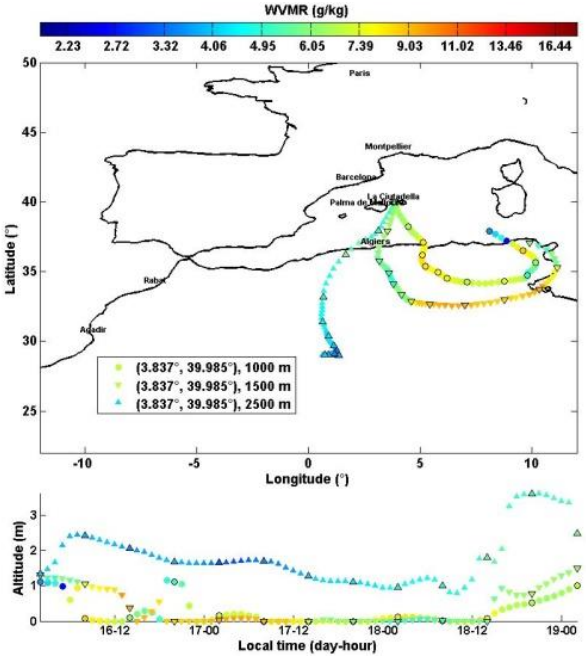

f)
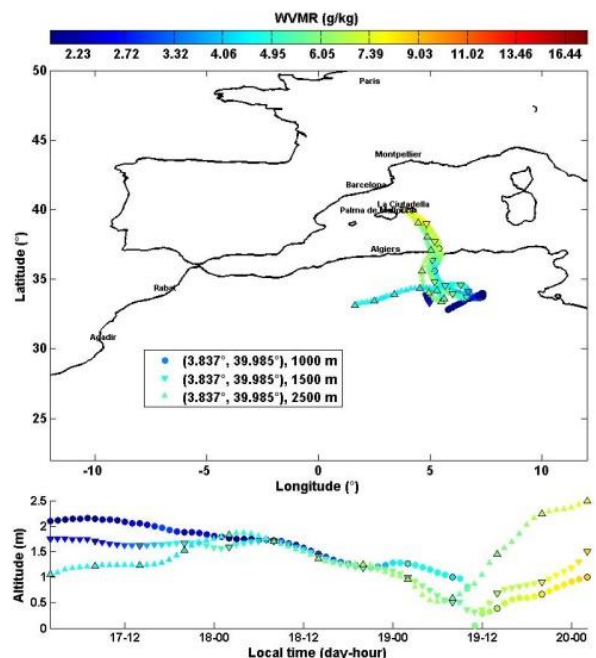

Figure 12. Back trajectories between 17 and 20 October 2012, computed using the HYSPLIT model (courtesy of NOAA Air Resources Laboratory, http://www.arl.noaa.gov). The wind fields are from GDAS (Global Data Assimilation System, http://www.ncep.noaa.gov/) at a horizontal resolution of $0.5^{\circ}$. The terminal location of the air masses is the site of Ciutadella for the altitudes $1,1.5$ and $2.5 \mathrm{~km}$ a.m.s.1. The color scheme represents the water vapor mixing ratio (WVMR) along the trajectories. 
Table 2. Analysis of the dust event of 17-20 October over Menorca: different dust layers and their lidar-derived mean water vapor mixing ratio $\overline{r_{\mathrm{H}}}$ and aerosol optical properties for seven different time periods. The main dust layers are highlighted in bold.

\begin{tabular}{|c|c|c|c|c|c|c|c|}
\hline Date, hour (LT) & $\begin{array}{l}\text { Altitude } \\
\text { range }(\mathrm{km})\end{array}$ & AOT a & 0.25 to $5 \mathrm{~km})$ & $\begin{array}{l}\overline{r_{\mathrm{H}}} \\
\left(\mathrm{g} \mathrm{kg}^{-1}\right)\end{array}$ & & $\overline{\mathrm{LR}}(\mathrm{sr})$ & PD̄R \\
\hline $17,00: 00-03: 00$ & $\begin{array}{l}0.3-1.0 \\
2-3.5\end{array}$ & $\sim 0.07$ & $\begin{array}{l}0.04 \\
<0.01\end{array}$ & $\begin{array}{l}8.8 \pm 0.6 \\
2.8 \pm 0.3\end{array}$ & 74 & $\begin{array}{l}67 \pm 8 \\
-\end{array}$ & $\begin{array}{l}0.01 \pm<0.01 \\
-\end{array}$ \\
\hline 18, 00:00-03:00 & $\begin{array}{l}0.3-0.5 \\
0.5-2.0\end{array}$ & $\sim 0.17$ & $\begin{array}{l}0.03 \\
0.09\end{array}$ & $\begin{array}{l}10.0 \pm 3 \\
6.4 \pm 0.4\end{array}$ & 45 & $\begin{array}{l}66 \pm 3 \\
47 \pm 6\end{array}$ & $\begin{array}{l}0.1 \pm 0.01 \\
0.1 \pm 0.01\end{array}$ \\
\hline $18,10: 30-14: 30$ & $\begin{array}{l}0.3-1 \\
\mathbf{1 . 5 - 3}\end{array}$ & $\sim 0.38$ & $\begin{array}{l}0.06 \\
\mathbf{0 . 2 1}\end{array}$ & $\begin{array}{l}7.9 \pm 2 \\
-\end{array}$ & 59 & $\begin{array}{l}- \\
-\end{array}$ & $\begin{array}{l}0.15 \pm 0.02 \\
0.16 \pm 0.01\end{array}$ \\
\hline $18,21: 00-24: 00$ & $\begin{array}{l}0.5-1.5 \\
\mathbf{1 . 5}-\mathbf{4}\end{array}$ & $\sim 0.29$ & $\begin{array}{l}0.09 \\
\mathbf{0 . 1 2}\end{array}$ & $\begin{array}{l}5.8 \pm 0.4 \\
\mathbf{4 . 1} \pm \mathbf{0 . 4}\end{array}$ & 71 & $\begin{array}{l}69 \pm 7 \\
\mathbf{6 3} \pm \mathbf{2}\end{array}$ & $\begin{array}{l}0.16 \pm 0.01 \\
\mathbf{0 . 1 9} \pm \mathbf{0 . 0 1}\end{array}$ \\
\hline 19, 00:00-03:00 & $\begin{array}{l}0.5-1.5 \\
\mathbf{2 - 3 . 5}\end{array}$ & $\sim 0.38$ & $\begin{array}{l}0.09 \\
\mathbf{0 . 1 2}\end{array}$ & $\begin{array}{l}6.3 \pm 0.8 \\
\mathbf{4 . 0} \pm \mathbf{0 . 2}\end{array}$ & 63 & $\begin{array}{l}58 \pm 8 \\
\mathbf{5 3} \pm \mathbf{2}\end{array}$ & $\begin{array}{l}0.12 \pm 0.01 \\
\mathbf{0 . 1 8} \pm \mathbf{0 . 0 1}\end{array}$ \\
\hline 19, 03:00-06:00 & $\begin{array}{l}0.3-1.0 \\
\mathbf{1 . 0}-\mathbf{3 . 5}\end{array}$ & $\sim 0.46$ & $\begin{array}{l}0.07 \\
\mathbf{0 . 3 2}\end{array}$ & $\begin{array}{l}7.2 \pm 2 \\
\mathbf{4 . 7} \pm \mathbf{1}\end{array}$ & 60 & $\begin{array}{l}69 \pm 15 \\
\mathbf{6 0} \pm \mathbf{4}\end{array}$ & $\begin{array}{l}0.15 \pm 0.02 \\
\mathbf{0 . 1 8} \pm \mathbf{0 . 0 1}\end{array}$ \\
\hline 20, 00:00-03:00 & $\begin{array}{l}0.5-1.0 \\
1.0-2.5\end{array}$ & $\sim 0.14$ & $\begin{array}{l}0.03 \\
0.07\end{array}$ & $\begin{array}{l}7.6 \pm 0.2 \\
6.7 \pm 0.5\end{array}$ & 53 & $\begin{array}{l}59 \pm 7 \\
40 \pm 2\end{array}$ & $\begin{array}{l}0.10 \pm 0.01 \\
0.10 \pm 0.01\end{array}$ \\
\hline
\end{tabular}

layer $\left(>7 \mathrm{~g} \mathrm{~kg}^{-1}\right)$ is also present above the MBL where the aerosols are trapped. From the air mass back trajectories shown in Fig. 12, it appears that this layer might be mainly off the Balearic Islands. Note that the rawinsounding from Palma de Majorca shows strong similarities with the lidarderived WVMR profile between the surface and $5 \mathrm{~km}$ a.m.s.l. (Fig. 14). It is therefore very likely that the same air mass was sampled above the two sites. Above $2 \mathrm{~km}$ a.m.s.l. the free troposphere is sampled by the lidar with a wet layer (WVMR $\sim 2-3 \mathrm{~g} \mathrm{~kg}^{-1}$ ) between 2 and $3.5 \mathrm{~km}$ a.m.s.l. The aerosol load in this layer is very low and non-depolarizing.

During the night of 17-18 October 2012, the strong prevailing winds veer to the south, bringing relatively warm and humid air masses from the Sahara to Menorca, because of the presence of a cut-off over Ireland, which moves east during the event. Thus, Saharan air masses penetrate over the Mediterranean from the Algerian coast (Figs. 12 and 13). The Sahara region is the world's largest source of naturally wind-blown mineral dust aerosol (Mahowald et al.., 1999; Prospero et al.., 2002), and the aerosol column burden may be strongly enhanced over the Mediterranean when wind blows from the African coast (e.g., Hamonou et al., 1999; Mona et al.., 2012). The AOT (PDR) increases significantly from 0.1 to 0.18 (0.01 to 0.10 ), whereas the LR decreases to reach $\sim 45 \mathrm{sr}$, which is a typical lidar ratio value for dustrelated aerosols (e.g., Müller et al., 2007; Mona et al., 2012). Stronger winds $\left(>10 \mathrm{~m} \mathrm{~s}^{-1}\right)$ are linked to a higher WVMR $\left(\sim 10 \mathrm{~g} \mathrm{~kg}^{-1}\right)$ in the lower tropospheric layers. Dust aerosols are present in the MBL, but the main dust layer is between 0.5 and $2.2 \mathrm{~km}$ a.m.s.l. associated with a high water vapor content, $r_{\mathrm{H}} \sim 6 \mathrm{~g} \mathrm{~kg}^{-1}$, which contrasts sharply with the low water vapor content of the above free troposphere. Similar observations can be made for the following day. The presence of large amounts of water vapor in the dust aerosol layers, between 4 and $6.7 \mathrm{~g} \mathrm{~kg}^{-1}$, may contribute to keeping the particles in well-defined vertical structures along their transport for a longer period of time. The static stability of the layer can be enhanced as described by Kim et al. (2004, 2009). In return, dust plumes can act on the high precipitation events that occurred during the experimental period by leading to the destabilization of the air masses coming from the sea that crossed the regions of Valencia and Tarragona (Spain) and upstream from Lourdes (France), where a $24 \mathrm{~h}$ accumulated rainfall of $\sim 50 \mathrm{~mm}$ occurred on 20 October. The presence of dust aerosol in the atmospheric column impacts the radiative balance and consequently modifies the vertical equilibrium by increasing the convection processes.

The conditions of atmospheric transport for 18 and 19 October are presented in Figs. 12, 13 and 15. They confirm what has been described for the morning of 18 October. As the low moved eastward, the wind weakened and the event ended on 20 October (Figs. 12 and 15). The end of the event is associated with intense rainfalls related to the high humidity of the Saharan air masses, which underwent subsidence over the Mediterranean Sea, while they captured water above the sea. Thus, the WVMR may have reached more than $15 \mathrm{~g} \mathrm{~kg}^{-1}$ at ground level (Fig. 14). These high humidity amounts are correlated with the higher aerosol extinction coefficients, probably due to the hygroscopic growth of certain particle types. A mix of various aerosol types seems to exist in the MBL because the PDR remains high in this layer. During all the events, the PDR varied from 0.1 to 0.19 
a)

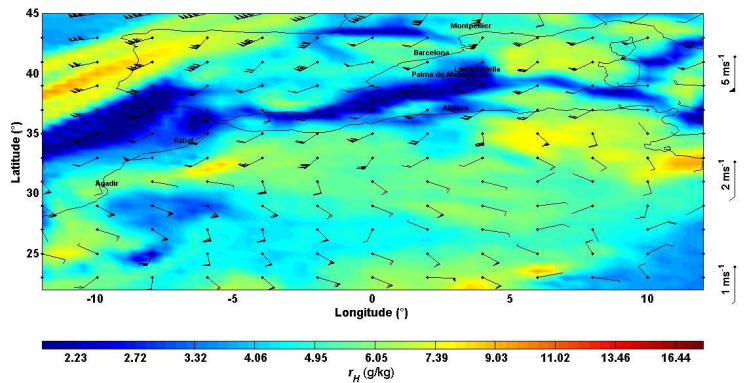

b)

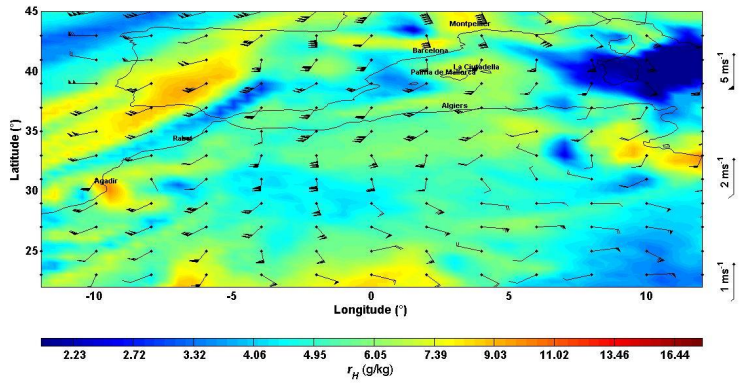

c)

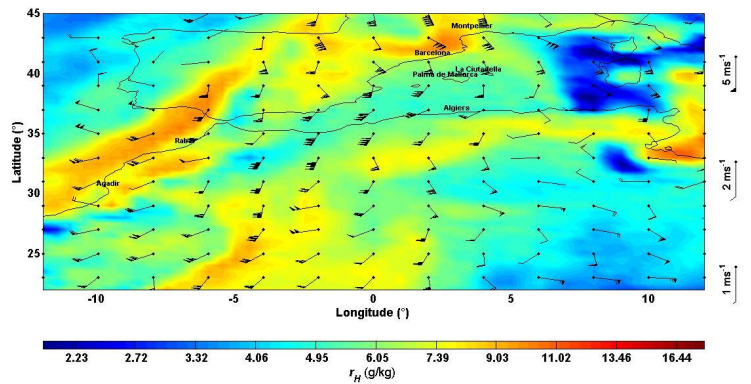

Figure 13. Wind-field (wind barbs) and water vapor mixing ratio $\left(\gamma_{\mathrm{H}}\right)$ (color plot) from ECMWF OPERA $0.5^{\circ}$ horizontal resolution analysis at $850 \mathrm{hPa}$ level for 17 October at 02:00 LT (a); 18 October, 02:00 LT (b); and 18 October, 14:00 LT (c).

in the aerosol layers (Table 2). Such values are very close to the ones derived by Müller et al. (2007) with the Raman lidar POLIS in the framework of the Saharan Mineral Dust Experiment (SAMUM) with PDR $=0.25 \pm 0.08$. Conversely, the LR presents more significant differences between the encountered aerosol layers during our experiments. In the MBL, the LR derived from our study is found to be generally higher ( $\sim 70 \mathrm{sr})$, which is in contrast to what can be expected for marine aerosols with a coarse mode of sea salt whose LR is $\sim 25 \mathrm{sr}$ (e.g., Flamant et al., 2000). Our derived LR value can be questioned for two reasons. Firstly, LR estimation in the altitude range of the MBL is more sensitive than in the upper aerosol layers to the estimated lidar overlap function. Secondly, edge effects of the regularization method used to retrieve the aerosol optical properties in night conditions can strongly impact the derivation of the optical properties in the lower levels. Note that high values of LR were also retrieved on 17 October when no dust event occurred. Again, the corresponding result could be questioned because the AOT is rather small, close to 0.07 , and the retrieval procedure could be under-constrained. However, the calculated uncertainty is about $30 \%$ (e.g., Chazette et al., 2012b), which confirms the probable higher values of the lidar ratio in the MBL.

For the upper layers that contains more dust aerosols, likely originated from Sahara only as indicated by larger VDR, the LR ranges from 47 to $63 \mathrm{sr}$. Its variability is significant over the four days sampled. This is an indication of changing aerosol optical properties and possibly of the particle nature. Different dust sources are active along the sampled air mass, as the low moves eastward, resulting in different types of dust particles being transported. Moreover, human activities close to the coast may also explain a part of this variability. The lidar-derived LR range can be compared to other literature results. During AMMA, Chazette et al.. (2007) found a LR between 40 and $67 \mathrm{sr}$ at $355 \mathrm{~nm}$ for the Harmattan dust layer above Niamey. During the same project, Kim et al. (2009) analyzed the CALIOP measurements and reported a value of mean lidar ratio at $532 \mathrm{~nm}$ : $\overline{\mathrm{LR}} \sim 36-38$ sr. Note that LR generally increases when the wavelength decreases. Cattrall et al. (2005) also reported $\overline{\mathrm{LR}}$ values close to $43 \mathrm{sr}$ using sun-photometer measurements. Dulac and Chazette (2003) found a $\overline{\mathrm{LR}}$ of $59 \mathrm{sr}$ at $532 \mathrm{~nm}$ for a multilayer aerosol structure with desert, anthropogenic and marine particles over the Mediterranean. Moreover, Mattis et al. (2002) used the Raman lidar technique to measure the LR value of elevated dust layers during two episodes over Germany. They report LR values between $\sim 50$ and $77 \mathrm{sr}$ at $532 \mathrm{~nm}$. Again, with a Raman lidar, Balis et al.. (2004) report LR values between 45 and $55 \mathrm{sr}$ at $355 \mathrm{~nm}$ for a dust event over Thessaloniki.

\section{Conclusions}

Raman lidar systems are powerful tools for profiling both water vapor and aerosols at high vertical resolution (between 15 and $50 \mathrm{~m}$ ). Recent improvements in the technology of detectors, optics and electronics allow for accurate and reliable instruments that provide new capabilities in response to the increasing needs for the cycles of these atmospheric components to be studied. New scientific and operational capabilities (unavailable with current large instruments) are now achieved with the eye-safe transportable Raman lidar WALI equipped with compact refractive telescopes for versatile measurements in the whole troposphere. The present paper focuses on the simultaneous retrieval of the WVMR and aerosol optical properties from the WALI instrument. It describes a detailed calibration procedure and a method for assessing the uncertainty budget on the derived WVMR.

The innovative design of the WALI system leads to very good capabilities in terms of low-altitude overlap and WVMR retrieval during nighttime - that is to say, with an absolute deviation from rawinsoundings of less than $0.5 \mathrm{~g} \mathrm{~kg}^{-1}$. The calibration procedure is the main error source for the lidar-derived WVMR when dealing with large SNR values. 
a)

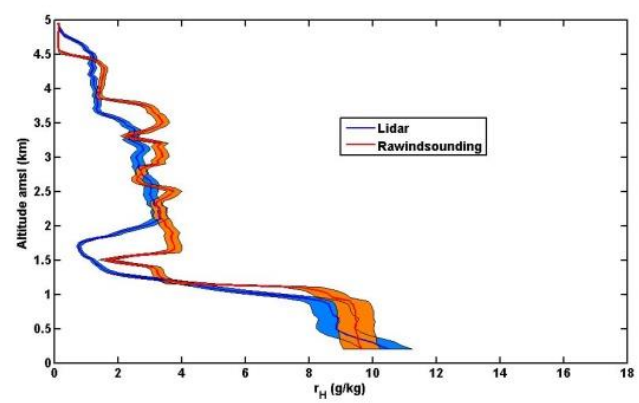

c)

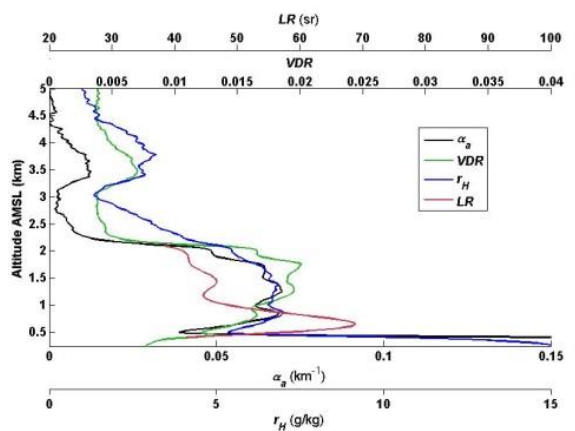

e)

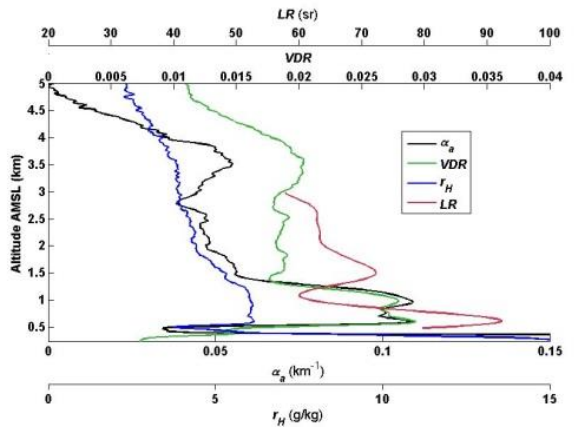

g)

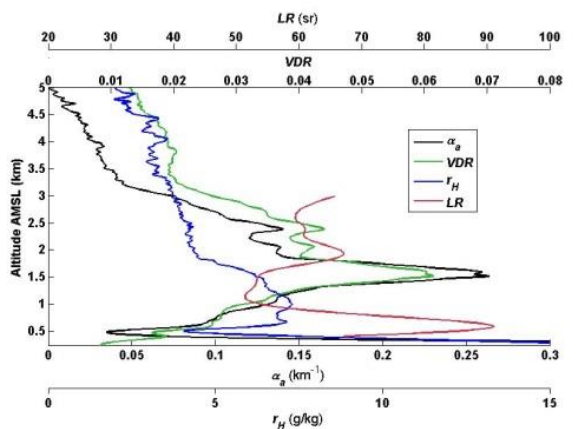

b)

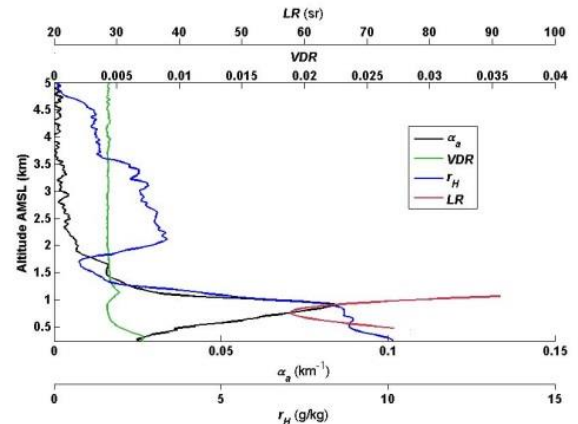

d)

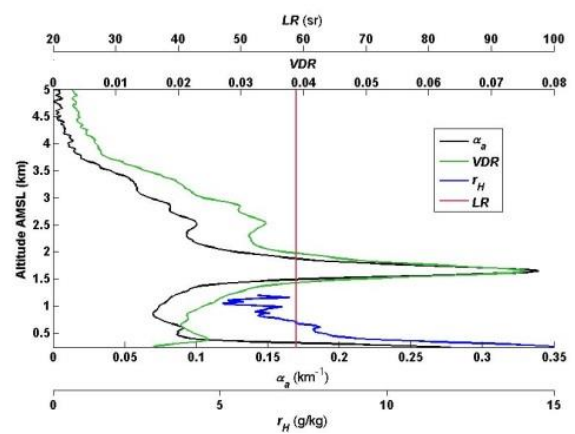

f)

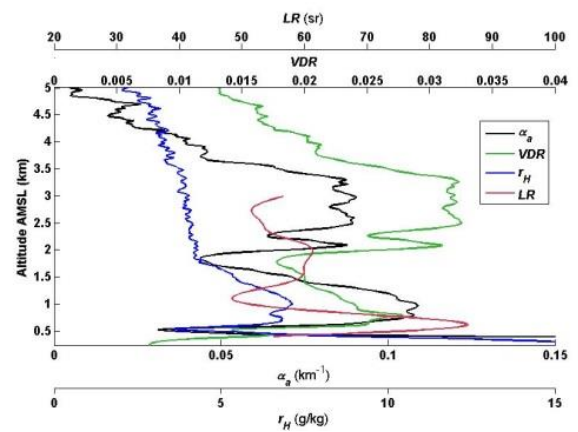

h)

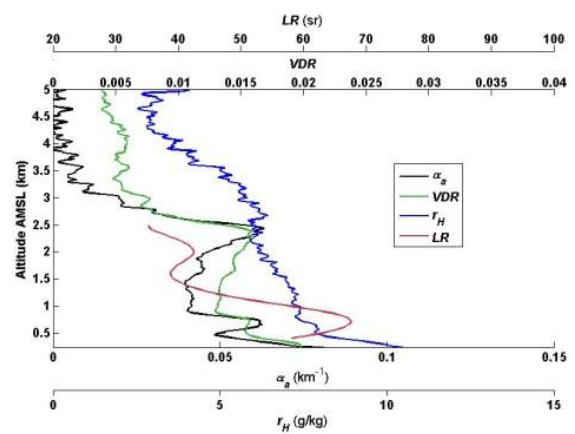

Figure 14. Comparison between lidar-derived water vapor mixing ratio (WVMR, $\gamma_{\mathrm{H}}$ ) and rawinsounding on 17 October, 00:00-03:00 LT (a), and WALI-derived parameters: extinction coefficient $\left(\alpha_{\mathrm{a}}\right)$, volume depolarization ratio (VDR), WVMR $\left(\gamma_{\mathrm{H}}\right)$ and lidar ratio (LR) for sampled times of Table 2, i.e., 17 October, 00:00-03:00 LT (b); 18 October, 00:00-03:00 LT (c); 18 October, 10:30-14:30 LT (d); 18 October, 21:00-00:00 LT (e); 19 October, 00:00-03:00 LT (f); 19 October, 03:00-06:00 LT (g); and 20 October, 00:00-03:00 LT (h). 

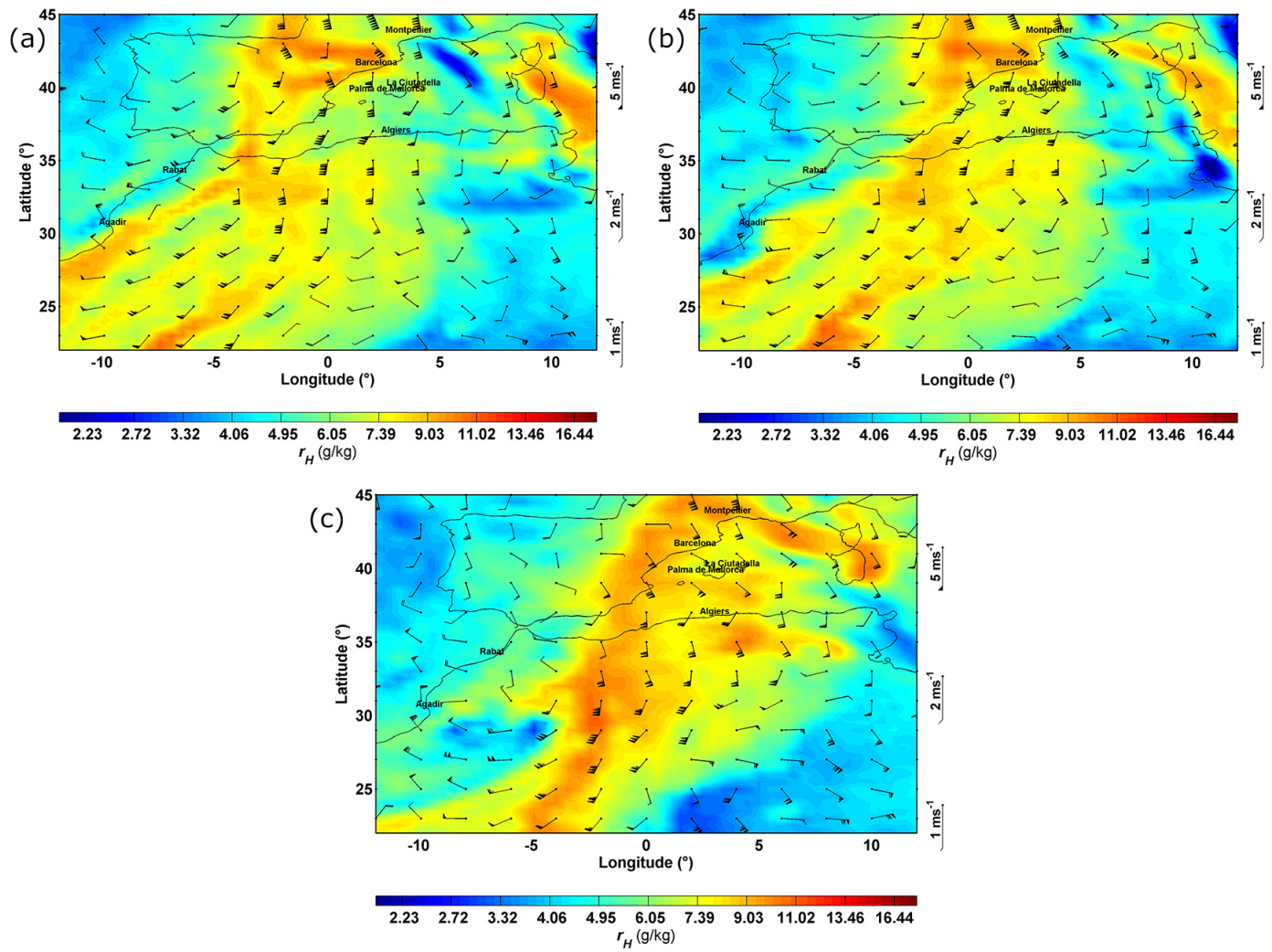

Figure 15. Wind-field (wind barbs) and water vapor mixing ratio (WVMR $\gamma_{\mathrm{H}}$ ) (color plot) from ECMWF OPERA $0.5^{\circ}$ horizontal resolution analysis at $850 \mathrm{hPa}$ level for 19 October at 02:00 LT (a); 19 October, 08:00 LT (b); and 20 October, 02:00 LT (c).

This error is driven by the reference rawinsounding accuracy and precision. It reaches $11 \%$ in the MBL and improves to $7 \%$ up to $5 \mathrm{~km}$ range for a temporal averaging of $20 \mathrm{~min}$ and a vertical resolution of $15 \mathrm{~m}$. The precision of measurements can deteriorate very quickly upwards due to the decreasing SNR with increasing altitude. The determination of the water vapor profile is more difficult during daytime, but the measurements have been performed with the same uncertainty below $1 \mathrm{~km}$ altitude using temporal averaging over $\sim 1 \mathrm{~h}$.

The uncertainties linked to the retrieval of aerosol optical properties with a relative error less than $10 \%$ for the LR or the PDR are comparable to those derived from previous mobile Raman lidars developed in our team.

To demonstrate its performances for measuring the WVMR and the aerosol optical properties, the WALI system was operated on Menorca during fall of 2012 in the framework of the Mediterranean project HyMeX (IODAMED campaign). This new system operated in a continuous monitoring mode has enable us to highlight a strong event of desert dust aerosols associated with high water vapor amounts between 17 and 20 October 2012. Both the LR and PDR assigned to dust particles are quite variable but stay within the range of the variability reported in the literature, i.e., between $\sim 45$ and $63 \pm 6 \mathrm{sr}$ and between 0.1 and $0.19 \pm 0.01$, respectively. The corresponding dust aerosol layers are associated with a rather high WVMR of $\sim 4$ $6.7 \pm 0.4 \mathrm{~g} \mathrm{~kg}^{-1}$, which may have contributed to the intense precipitation events observed during this period over southwestern Europe.

Acknowledgements. This work is a contribution to the HyMeX and ChArMEx programs, sponsored by grants MISTRALS/HyMeX and project ANR-11-BS56-0005 IODA-MED. This work was also supported by the French Space Agency (CNES) and the Commissariat à l'Energie Atomique et aux énergies alternatives (CEA). We thank D. N. Whiteman for useful information for the development of the WALI instrument. We also thank M. Sicard for his help in installing the lidar station on Menorca. Claude Camy-Peyret and François Dulac are gratefully acknowledged for reviewing this paper in its final form. ECMWF data used in this study were obtained from the ECMWF data server. Meteo-France is gratefully acknowledged for the rawindsounding data and the output of the AROME-WMED model (10.6096/HYMEX.AROME_WMED.2012.02.20).

Edited by: J.-L. Attie

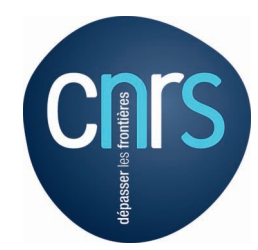

The publication of this article is financed by CNRS-INSU. 


\section{References}

Agusti-Panareda, A., Vasiljevic, D., Beljaars, A., Bock, O., Guichard, F., Nuret, M., Lafore, J.-P., Andersson, E., Bechtold, P., Fink, A., Hersbach, H., Garcia Mendez, A., Ngamini, J.-B., Parker, D. J., Redelsperger, J. L., and Tompkins, A.: Radiosonde humidity bias correction over the West African region for the special AMMA reanalysis at ECMWF, Q. J. Roy. Meteorol. Soc., 135, 595-617, doi:10.1002/qj.396, 2009.

Ansmann, A., Riebesell, M., Wandinger, U., Weitkamp, C., Voss, E., Lahmann, W., and Michaelis, W.: Combined raman elasticbackscatter LIDAR for vertical profiling of moisture, aerosol extinction, backscatter, and LIDAR ratio, Appl. Phys., B55, 18-28, 1992.

Balis, D. S., Amiridis, V., Nickovic, S., Papayannis, A., and Zerefos, C.: Optical properties of Saharan dust layers as detected by a Raman lidar at Thessaloniki, Greece, J. Geophys. Res., 31, L13104, doi:10.1029/2004GL019881, 2004.

Bock, O. and Nuret, M.: Verification of NWP model analyses and radiosonde humidity data with GPS precipitable water vapor estimates during AMMA, Weather Forecast., 24, 1085-1101, doi:10.1175/2009WAF2222239.1, 2009.

Boucher, O. and Anderson, L.: General circulation model assessment of the sensitivity of direct climate forcing by anthropogenic sulfate aerosols to aerosol size and chemistry, J. Geophys. Res., 100, 26117-26134, 1995.

Bribes J. L., Gaufres, R., Monan, M., Lapp, M., and Penney, C. M.: Raman band contours for water vapor as a function of temperature, Appl. Phys. Lett., 28, 336-337, 1976.

Bruneau, D., Quaglia, P., Flamant, C., Meissonnier, M., and Pelon, J.: Airborne Lidar LEANDRE II for Water vapor Profiling in the Troposphere. I. System description, Appl. Opt., 40, 3450-3461, 2001

Cattrall, C., Reagan, J., Thome, K., and Dubovik, O.: Variability of aerosol and spectral lidar and backscatter and extinction ratios of key aerosol types derived from selected Aerosol Robotic Network locations, J. Geophys. Res., 110, D10S11, doi:10.1029/2004JD005124, 2005.

Chazette, P.: The monsoon aerosol extinction properties at Goa during INDOEX as measured with lidar, J. Geophys. Res., 108, 4187, doi:10.1029/2002JD002074, 2003.

Chazette P., Couvert, P., Randriamiarisoa, H., Sanak, J., Bonsang, B., Moral, P., Berthier, S., Salanave, S., and Toussaint, F.: Three dimensional survey of pollution during winter in French Alps valleys, Atmos. Environ., 39, 1345-1047, 2005.

Chazette, P., Sanak, J., and Dulac, F.: New approach for aerosol profiling with a lidar onboard an ultralight aircraft: application to the African Monsoon Multidisciplinary Analysis, Environ. Sci. Technol., 41, 8335-8341, 2007.

Chazette, P., Raut, J.-C., Dulac, F., Berthier, S., Kim, S-W., Royer, P., Sanak, J., Loaëc, S., and Grigaut-Desbrosses, H.: Simultaneous observations of lower tropospheric continental aerosols with a ground-based, an airborne, and the spaceborne CALIOP lidar systems, J. Geophys. Res, 115, D00H31, doi:10.1029/2009JD012341, 2010.

Chazette, P., Dabas, A., Sanak, J., Lardier, M., and Royer, P.: French airborne lidar measurements for Eyjafjallajökull ash plume survey, Atmos. Chem. Phys., 12, 7059-7072, doi:10.5194/acp-127059-2012, 2012a.
Chazette, P., Bocquet, M., Royer, P., Winiarek, V., Raut, J.-C., Labazuy, P., Gouhier, M., Lardier, M., and Cariou, J.-P.: Eyjafjallajökull ash concentrations derived from both lidar and modeling, J. Geophys. Res., 117, D00U14, doi:10.1029/2011JD015755, 2012b.

Ciesielski, P. E., Johnson, R. H., Haertel, P. T., and Wang, J.: Corrected TOGA COARE sounding humidity data: Impact on diagnosed properties of convection and climate over the warm pool, J. Climate, 16, 2370-2384, 2003.

Collis, R. T. H. and Russell, P. B.: Lidar measurement of particles and gases by elastic backscattering and differential absorption in: Laser Monitoring of the Atmosphere, edited by: Hinkley, E. D., 71-152, Springler-Verlag, New York, 1976.

Cooney, J. A.: Remote measurements of atmospheric water vapor profiles using the Raman component of laser backscatter, J. Appl. Meteorol., 9, 182-184, 1970.

Draxler, R. R. and Rolph, G. D.: HYSPLIT (HYbrid Single-Particle Lagrangian Integrated Trajectory) Model access via NOAA ARL READY Website (http://www.arl.noaa.gov/ready/hysplit4.html), NOAA Air Resources Laboratory, Silver Spring, MD, 2003.

Dulac, F. and Chazette, P.: Airborne study of a multi-layer aerosol structure in the eastern Mediterranean observed with the airborne polarized lidar ALEX during a STAAARTE campaign (7 June 1997), Atmos. Chem. Phys., 3, 1817-1831, doi:10.5194/acp-31817-2003, 2003.

Ferrare, R., Turner, D., Clayton, M., Schmid, B., Redemann, J., Covert, D., Elleman, R., Ogren, J., Andrews, E., Goldsmith, J. E. M., and Jonsson, H.: Evaluation of daytime measurements of aerosols and water vapor made by an operational Raman lidar over the Southern Great Plains, J. Geophys. Res., 111, D05S08, doi:10.1029/2005JD005836, 2006.

Fiocco, G. and Grams, G.: Observations of the aerosol layer at $20 \mathrm{~km}$ by optical radar, J. Atmos. Sci., 21, 323-324, 1964.

Flamant C., Pelon, J., Chazette, P., Trouillet, V., Quinn, P., Frouin, R., Bruneau, D., Léon, J. F., Bates, T., Johnson, J., and Livingston, J.: Airborne lidar measurements of aerosol spatial distribution and optical properties over the Atlantic Ocean during an European pollution outbreak of ACE-2, Tellus, 52B, 662-667, 2000.

Fujiwara, M., Shiotani, M., Hasebe, F., Vömel, H., Oltmans, S. J., Ruppert, P. W., Horinouchi, T., and Tsuda, T.: Performance of the Meteolabor "Snow White" chilled-mirror hygrometer in the tropical troposphere: Comparisons with the Vaisala RS80 A/Hhumicap sensors, J. Atmos. Oceanic Technol., 20, 1534-1542, 2003.

Giorgi, F. and Lionello, P.: Climate change projections for the Mediterranean region, Global Planet. Change, 63, 90-104, 2008.

Hamonou, E., Chazette, P., Balis, D., Dulac, F., Schneider, X., Galani, E., Ancellet, G., and Papayannis, A.: Characterisation of the vertical structure of Saharan dust export to the Mediterranean basin, J. Geophys. Res., 18, 2257-2270, 1999.

Haywood, J. M., Roberts, D. L., Slingo, A., Edwards, J. M., and Shine, K. P.: General circulation model calculations of the direct radiative forcing by anthropogenic sulphate and fossil-fuel soot aerosol, J. Climate, 10, 1562-1577, doi:10.1175/1520-0442, 1997.

Held, I. M. and Soden, B. J.: Water vapor feedback and global warming, Annual Rev. Energy Environ., 25, 441-475, doi:10.1146/annurev.energy.25.1.441, 2000. 
Higdon, N. S., Browell, E. V., Ponsardin, P., Grossmann, B. E., Butler, C. F., Chyba, T. H., Mayo, M. N., Allen, R. J., Heuser, A. W., Grant, W. B., Ismail, S., Mayor, S. D., and Carter, A. F.: Airborne differential absorption lidar system for measurements of atmospheric water vapor and aerosols, Appl. Opt., 33, 6422-6438, 1994.

IPCC: Climate Change 2013: The physical science basis. Contribution of working group I to the fifth assessment report of the Intergovernmental Panel on Climate Change, edited by: Stocker, T. F., Qin, D., Plattner, G.-K., Tignor, M., Allen, S. K., Boschung, J., Nauels, A., Xia, Y., Bex, V., and Midgley, P. M., Cambridge University Press, Cambridge, United Kingdom and New York, NY, USA, 1535 pp., 2013.

Kim, S.-W., Yoon, S.-C., Jefferson, A., Won, J.-G., Dutton, E. G., Ogren, J. A., and Anderson, T. L.: Observation of enhanced water vapor in Asian dust layer and its effect on atmospheric radiative heating rates, Geophy. Res. Lett., 31, L18113, doi:10.1029/2004GL020024, 2004.

Kim, S.-W., Chazette, P., Dulac, F., Sanak, J., Johnson, B., and Yoon, S.-C.: Vertical structure of aerosols and water vapor over West Africa during the African monsoon dry season, Atmos. Chem. Phys., 9, 8017-8038, doi:10.5194/acp-9-8017-2009, 2009.

King, L. V.: On the complex anisotropic molecule in relation to the dispersion and scattering of light, Proc. Royal Soc. London, Series 1, 104, 333-357, 1923.

Klett, J. D.: Lidar inversion with variable backscatter/extinction ratios, Appl. Opt., 24, 1638-1643, 1985.

Larson, T. V. and Taylor, G. S.: On the evaporation of $\mathrm{NH}_{4} \mathrm{NO}_{3}$ aerosol, Atmos. Environ., 17, 2489-2595, 1983.

Mahowald, N., Kohfeld, K., Hansson, M., Balkanski, Y., Harrison, S. P., Prentice, I. C., Schulz, M., and Rodhe, H.: Dust sources and deposition during the last glacial maximum and current climate: A comparison of model results with paleodata from ice cores and marine sediments, J. Geophys. Res., 104, 15895-15916, 1999.

Mattis, I., Ansmann, A., Müller, D., Wandinger, U., and Althausen, D.: Dual-wavelength Raman lidar observations of the extinction to backscatter ratio of Saharan dust, Geophys. Res. Lett., 29, 9, doi:10.1029/2002GL014721, 2002.

Measures, R. M.: Laser remote sensing: Fundamentals and Applications, Wiley \& Sons, NewYork, 1984.

Melfi, S. H., Lawrence Jr., J. D., and McCormic, M. P.: Observation of Raman scattering by water vapor in the atmosphere, Appl. Phys. Lett., 15, 295-297, 1969.

Melfi, S. H., Whiteman, D. N., and Ferrare, R.: Observation of atmospheric fronts using Raman lidar moisture measurements, J. Appl. Meteorol., 28, 789-806, 1989.

Mona, L., Liu, Z., Müller, D., Omar, A., Papayannis, A., Pappalardo, G., Sugimoto, N., and Vaughan, M.: Lidar measurements for desert dust characterization: an overview, Adv. Meteorol., 2012, 1-36, doi:10.1155/2012/356265, 2012.

Müller, D., Ansmann, A., Mattis, I., Tesche, M., Wandinger, U., and co-authors: Aerosol-type-dependent lidar ratios observed with Raman lidar, J. Geophys. Res., 112, D16202, doi:10.1029/2006JD008292, 2007.

Nash, J., Smout, R., Oakley, T., Pathnack, B., and Kumosenko, S.: WMO Intercomparison of high quality radiosonde systems, Vacoas, Mauritius, 2-25 February 2005, WMO report, February 2005 (http://www.wmo.int/pages/prog/www/), 2005.
Nicolet, M.: On the molecular scattering in the terrestrial atmosphere, Planet. Space Sci., 32, 1467-1468, doi:10.1016/00320633(84)90089-8, 1984.

Penney, C. M. and Lapp, M.: Raman-scattering cross sections for water vapor, J. Opt. Soc. Am., 66, 422-425, 1976.

Prospero, J. M., Ginoux, P., Torres, O., Nicholson, S. E., and Gill, T. E.: Environmental characterization of global sources of atmospheric soil dust identified with the Nimbus 7 Total Ozone Mapping Spectrometer (TOMS) absorbing aerosol product, Rev. Geophys., 40, 1002, doi:10.1029/2000RG000095, 2002.

Randriamiarisoa, H., Chazette, P., Couvert, P., Sanak, J., and Mégie, G.: Relative humidity impact on aerosol parameters in a Paris suburban area, Atmos. Chem. Phys., 6, 1389-1407, doi:10.5194/acp-6-1389-2006, 2006.

Raut, J.-C. and Chazette, P.: Assessment of vertically-resolved $\mathrm{PM}_{10}$ from mobile lidar observations, Atmos. Chem. Phys., 9, 8617-8638, doi:10.5194/acp-9-8617-2009, 2009.

Reichardt, J., Wandinger, U., Klein, V., Mattis, I., Hilber, B., and Begbie, R.: RAMSES: German meteorological service autonomous Raman lidar for water vapor, temperature, aerosol, and cloud measurements, Appl. Opt., 51, 8111-8131, doi:10.1364/AO.51.008111, 2012.

Rood, M. J., Covert, D. S., and Larson, T. V.: Hygroscopic properties of atmospheric aerosol in Riverside, California, Tellus, 39B, 383-397, 1987.

Royer, P., Chazette, P., Lardier, M., and Sauvage, L.: Aerosol content survey by mini- $\mathrm{N}_{2}$-Raman lidar: Application to local and long-range transport aerosols, Atmos. Environ., 45, 7487-7495, doi:10.1016/j.atmosenv.2010.11.001, 2011.

Sanchez-Gomez, E., Somot, S., and Mariotti, A.: Future changes in the Mediterranean water budget projected by an ensemble of regional climate models, Geophys. Res. Lett., 36, L21401, doi:10.1029/2009GL040120, 2009.

Seity, Y., Brousseau, P., Malardel, S., Hello, G., Benard, P., Bouttier, F., Lac, C., and Masson, V.: The AROME-France convectivescale operational model, Mon. Weather Rev., 139, 976-991, doi:10.1175/2010MWR3425.1, 2011.

Tikhonov, A. E. and Arsenin, V. Y.: Solutions of ill-posed problems, Wiley, 1977.

Turner, D. D. and Goldsmith, J. E. M.: Twenty-four-hour Raman lidar water vapor measurements during the Atmospheric Radiation Measurement program's 1996 and 1997 water vapor intensive observation periods, J. Atmos. Oceanic Technol., 16, 10621076, 1999.

Vaughan, G., Wareing, D. P., Thomas, L., and Mitev, V.: Humidity measurements in the free troposphere using Raman backscatter, Q. J. Roy. Meteorol. Soc., 114, 1471-1484, 1988.

Veselovskii, I. A., Cha, H. K., Kim, D. H., Choi, S. C., and Lee, J. M.: Raman lidar for the study of liquid water and water vapor in the troposphere, Appl. Phys. B, 71, 113-117, doi:10.1007/s003400000290, 2000.

Wang, J. and Zhang, L.: Systematic errors in global radiosonde precipitable water data from comparison with ground-based GPS measurements, J. Climate, 21, 2218-2238, 2008.

Wang, J., Cole, H. L., Carlson, D. J., Miller, E. R., and Beierle, K.: Corrections of humidity measurement error from the Vaisala RS80 radiosonde - application to TOGA COARE data, J. Atmos. Oceanic Technol., 19, 981-1002, 2002. 
Whiteman, D. N., Melfi, S. H., and Ferrare, R. A.: Raman lidar system for the measurement of water vapor and aerosols in the earth's atmosphere, Appl. Opt., 31, 3068-3082, 1992.

Whiteman, D. N., Rush, K., Veselovskii, I., Cadirola, M., Comer, J., Potter, J. R., and Tola, R.: Demonstration measurements of water vapor, cirrus clouds, and carbon dioxide using a highperformance Raman lidar, J. Atmos. Oceanic Technol., 24, 1377$1388,2007$.
Yoon, S.-C., Kim, S.-W., Kim, J., Sohn, B.-J., Jefferson, A., Choi, S.-J., Cha, D.-H., Lee, D-K., Anderson, T. L., Doherty, S. J., and Weber, R. J.: Enhanced water vapor in Asian dust layer: entrainment processes and implication for aerosol optical properties, Atmos. Environ., 40, 2409-2421, 2006. 